\title{
Multiple-Radar Data Assimilation and Short-Range Quantitative Precipitation Forecasting of a Squall Line Observed during IHOP_2002
}

\author{
Qingnong XiaO and JuAnZhen Sun \\ Mesoscale and Microscale Meteorology Division, National Center for Atmospheric Research,* Boulder, Colorado
}

(Manuscript received 20 July 2006, in final form 11 December 2006)

\begin{abstract}
The impact of multiple-Doppler radar data assimilation on quantitative precipitation forecasting (QPF) is examined in this study. The newly developed Weather Research and Forecasting (WRF) model Advanced Research WRF (ARW) and its three-dimensional variational data assimilation system (WRF 3DVAR) are used. In this study, multiple-Doppler radar data assimilation is applied in WRF 3DVAR cycling mode to initialize a squall-line convective system on 13 June 2002 during the International $\mathrm{H}_{2} \mathrm{O}$ Project (IHOP_2002) and the ARW QPF skills are evaluated for the case. Numerical experiments demonstrate that WRF 3DVAR can successfully assimilate Doppler radial velocity and reflectivity from multiple radar sites and extract useful information from the radar data to initiate the squall-line convective system. Assimilation of both radial velocity and reflectivity results in sound analyses that show adjustments in both the dynamical and thermodynamical fields that are consistent with the WRF 3DVAR balance constraint and background error correlation. The cycling of the Doppler radar data from the 12 radar sites at 2100 UTC 12 June and 0000 UTC 13 June produces a more detailed mesoscale structure of the squall-line convection in the model initial conditions at 0000 UTC 13 June. Evaluations of the ARW QPF skills with initialization via Doppler radar data assimilation demonstrate that the more radar data in the temporal and spatial dimensions are assimilated, the more positive is the impact on the QPF skill. Assimilation of both radial velocity and reflectivity has more positive impact on the QPF skill than does assimilation of either radial velocity or reflectivity only. The improvement of the QPF skill with multiple-radar data assimilation is more clearly observed in heavy rainfall than in light rainfall. In addition to the improvement of the QPF skill, the simulated structure of the squall line is also enhanced by the multiple-Doppler radar data assimilation in the WRF 3DVAR cycling experiment. The vertical airflow pattern shows typical characteristics of squall-line convection. The cold pool and its related squall-line convection triggering process are better initiated in the WRF 3DVAR analysis and simulated in the ARW forecast when multiple-Doppler radar data are assimilated.
\end{abstract}

\section{Introduction}

The U.S. Weather Research Program (USWRP) identified quantitative precipitation forecasting (QPF) as one of the major areas with priorities for research and development (Fritsch and Carbone 2004). To fulfill these research needs, a multiagency and international field experiment, the International $\mathrm{H}_{2} \mathrm{O}$ Project

\footnotetext{
* The National Center for Atmospheric Research is sponsored by the National Science Foundation.
}

Corresponding author address: Dr. Qingnong Xiao, Mesoscale and Microscale Meteorology Division, National Center for Atmospheric Research, P.O. Box 3000, Boulder, CO 80307-3000.

E-mail: hsiao@ucar.edu
(IHOP_2002), was launched in Texas, Oklahoma, and Kansas. The overarching goal of this experiment was to investigate the characterization of the four-dimensional distribution of water vapor and its application to improving our understanding and prediction of convection (Weckwerth et al. 2004). An accurate short-range QPF of convective systems is an ultimate objective of the program and a key indication of how well the collected observations are used in the model initial conditions.

The IHOP_2002 field campaign took advantage of existing observing systems in the southern Great Plains of the United States, including the well-distributed Weather Surveillance Radar-1988 Doppler (WSR-88D) units in the region. For convective storms and related mesoscale and microscale systems, radar has played a

DOI: $10.1175 / M W R 3471.1$

(C) 2007 American Meteorological Society 
prominent role in revealing their structures (Wakimoto et al. 2004). The echo patterns and Doppler velocity wind syntheses have been compared with numerical simulations in order to verify whether the simulations generated realistic results in a few studies (Germann and Zawadski 2002; Sun 2005). While radar observation verifications have led to significant advances in our understanding of convection, how to use the observations in model initial conditions for improving simulation and QPF is still a challenging problem. Most of the operational centers still use large-scale analyses to initialize mesoscale or microscale convective systems. If we can successfully assimilate the Doppler radar data from its high-resolution network into numerical models, the convective systems will be better represented in model initial conditions. The prediction of the initiation, location, and timing of convective storms and short-range QPF skill could be improved significantly.

To achieve this goal, active scientific research has been conducted in recent years to assimilate WSR-88D level II data. The earliest analysis of the dynamical and microphysical structures of convective storms can be traced back to Ziegler (1985), although that study was not for numerical prediction. Sun and Crook (1997, 1998) developed a four-dimensional variational data assimilation (4DVAR) scheme for the initialization of a cloud-scale model with single-Doppler radar observations. The 4DVAR technique was able to provide balanced initial fields with the model by minimizing the differences between the radar observations (radial velocity and reflectivity) and the model equivalents. Weygandt et al. (2002a,b) introduced a sequential initialization technique using single-Doppler observations. The technique involved the sequential application of a simple single-Doppler retrieval technique (Shapiro et al. 1995), a thermodynamical retrieval technique, and a moisture adjustment step. Dowell et al. (2004) applied an ensemble Kalman filter technique (Evensen 1994; Snyder and Zhang 2003; Zhang et al. 2004) to initialize the cloud model developed by Sun and Crook $(1997,1998)$. Tong and Xue (2005) used a similar technique for assimilation of Doppler radar data with a compressible nonhydrostatic model. Because of the significant computational cost of 4DVAR and ensemble Kalman filter, however, both methods have been primarily used in the research mode for the convective-scale application.

A practical method for Doppler radar data assimilation is via the three-dimensional variational (3DVAR) approach (Gao et al. 1999, 2004; Xiao et al. 2005, 2007). In recent years, the National Center for Atmospheric Research (NCAR) has partnered with the Korea Meteorological Administration (KMA) to develop Dopp- ler radar data assimilation capability (Xiao et al. 2005, 2007) for KMA operational applications based on the fifth-generation Pennsylvania State UniversityNational Center for Atmospheric Research Mesoscale Model (MM5) 3DVAR system (Barker et al. 2004). As an alternative to 4DVAR, the cycling 3DVAR can also integrate model information and assimilate observations at different times into the initial field; however, its computational cost is much lower. Applications of the MM5 3DVAR radar data assimilation system to a frontal rainband and a hurricane observed by a Korean radar demonstrated that the radar observations improved the rainfall forecasts (Xiao et al. 2005, 2007). During the past years, the development of WRF-ARW (Skamarock et al. 2005) has been accelerated. Our development of the regional 3DVAR Doppler radar data assimilation is now focusing on ARW analysis. Another 3DVAR-based radar data assimilation system has been developed at the Center for Analysis and Prediction of Storms (CAPS) for the Advanced Regional Prediction System (ARPS) model (Gao et al. 1999, 2004). The ARPS 3DVAR scheme was recently employed in a case study of a cluster of thunderstorms to assimilate single-Doppler observations and predicted each individual thunderstorm with reasonable success (Hu et al. 2006).

The main objective of this study is to evaluate the impact of the WRF 3DVAR with multiple-Dopplerradar data assimilation on QPF. A real-data case of a squall line that occurred in Oklahoma and Kansas on 12-13 June 2002 during IHOP_2002 is chosen for this study. This case was documented by 12 ground-based Doppler radars in Oklahoma, Kansas, and Texas. Detailed analyses of the case were conducted by Weckwerth et al. (2004) and Wakimoto et al. (2004). In this study, we focus on ARW short-range QPF with multiple-Doppler radar data assimilation to examine the performance of Doppler radar data assimilation capability in WRF 3DVAR. Since this is our first real-data study on multiple-Doppler radar data assimilation using WRF 3DVAR, the results are of great value for further improvement of the WRF 3DVAR and for the development of similar systems by other institutions.

This manuscript is organized as follows. In section 2, the IHOP_2002 squall line, Doppler radar observations, and precipitation are described. The WRF 3DVAR formulation for Doppler radar data assimilation and other technical issues are given in section 3. In section 4, we describe the experimental design for this study. We present the results of the multiple-Dopplerradar data assimilation experiments in section 5. The evaluation of the ARW QPF skills is shown in section 6. We also present some sensitivity studies of the QPF to 
different setups of the initialization technique in this section. Section 7 further examines the characteristics of the forecast with multiple-Doppler radar data assimilation. The last section (section 8 ) provides a summary and draws some conclusions.

\section{Overview of the squall-line case}

\section{a. Case description}

From 12 through 13 June 2002, several bands of thunderstorms occurred in the IHOP_2002 domain. This study focuses on a northeast-to-southwest-oriented squall line from the Kansas and Oklahoma border to the Texas Panhandle, initiated at around 2100 UTC 12 June 2002. Figure 1a shows the surface observations and three intersecting boundaries, overlaid with a Doppler radar mosaic at 2100 UTC 12 June 2002. The dryline was generated by the convergence of a moist southerly flow coming from the Gulf of Mexico, and a drier continental air mass. A remnant outflow boundary from a mesoscale convective system that developed over Kansas after 2200 UTC 11 June 2002 was still shown at 2100 UTC 12 June (Fig. 1a). The dryline in front of the cold front intersected the outflow boundary, forming a "triple point" east of the Oklahoma panhandle near the Kansas and Oklahoma border (Weckwerth et al. 2007, manuscript submitted to Mon. Wea. Rev.).

Isolated convections formed from the Kansas and Oklahoma border to the Texas Panhandle along the dryline at 2100 UTC 12 June (Fig. 1a). They gradually strengthened along most of the dryline, and a severe storm developed near the triple point. This storm produced golf-ball-sized hail, maximum outflow wind speeds exceeding $30 \mathrm{~m} \mathrm{~s}^{-1}$, flashing flooding, and at least one tornado (Wakimoto et al. 2004). At 0000 UTC 13 June, a squall-line structure was well developed in the reflectivity field (Fig. 1b), with the intense convection in the triple-point area near the Kansas and Oklahoma border. It then moved southeastward and dissipated after 0900 UTC 13 June 2002.

\section{b. Doppler radar observations}

Figure $1 \mathrm{~b}$ shows the locations of the 12 WSR-88Ds whose data are used for the data assimilation experiments. The squall line from its initiation (at around 2100 UTC 12 June) to 0000 UTC 13 June was well covered by the reflectivity mosaic of the 12 radar observations. We conducted quality control of the radial velocity and reflectivity data from the 12 radars for both 2100 UTC 12 June and 0000 UTC 13 June 2002. The method of Doppler radar data quality control and other preprocessing procedures (data thinning and es- timation of radar observation errors) are the same as described in Xiao et al. (2005, 2007).

It is noted that the Doppler radar at Vance Air Force Base (radar site VNX), Oklahoma, stands in a critical position for observing the convective band at both 2100 UTC 12 June (Fig. 1a) and 0000 UTC 13 June (Fig. 1b). Data assimilation experiments were performed using single-Doppler radar observations from VNX to compare the relative importance of multiple- versus singleradar data assimilation to the QPF skill.

\section{c. Precipitation}

During the 9-h period from 0000 to 0900 UTC 13 June, heavy rainfall from the squall line was recorded in Kansas, Missouri, Oklahoma, and Texas. Figure 2 presents 3-h accumulated precipitation from the stage IV analysis of the National Centers for Environmental Prediction (NCEP). The maximum 3-h rainfall amount was $89.5 \mathrm{~mm}$ at 0300 UTC in northern Oklahoma near the southern border of Kansas. It was $72.9 \mathrm{~mm}$ over the southwestern corner of Missouri at 0600 UTC, and 69.8 mm on the border of Missouri and Arkansas at 0900 UTC. The rainband collapsed after 0900 UTC while another mesoscale system moved in and caused the heavy rainfall in the Texas Panhandle. Rainfall verification is one of the main components of this study. By rainfall verification, we will explore the ARW QPF skill with the multiple-Doppler radar data assimilation for this squall-line case.

\section{Methodology of Doppler radar data assimilation in WRF 3DVAR}

\section{a. Brief description of the WRF $3 D V A R$ system}

The WRF 3DVAR is a component of the newly developed WRF variational data assimilation (WRFVAR) system. The WRF-VAR is intended to include both 3DVAR and 4DVAR capabilities within a common framework, although the 4DVAR is still under development. The WRF 3DVAR originated and evolved from the MM5 3DVAR (Barker et al. 2004), but the basic software interface and coordinate framework are fully updated for the WRF-ARW model (Skamarock et al. 2005). Here, we provide a brief summary of the system. The reader is referred to the above two publications for further details.

Based on the notation for data assimilation (Ide et al. 1997), the cost function in WRF 3DVAR is

$$
\begin{aligned}
J(\mathbf{x})= & J^{b}+J^{o}=\frac{1}{2}\left(\mathbf{x}-\mathbf{x}^{b}\right)^{\mathrm{T}} \mathbf{B}^{-1}\left(\mathbf{x}-\mathbf{x}^{b}\right) \\
& +\frac{1}{2}\left(\mathbf{y}-\mathbf{y}^{o}\right)^{\mathrm{T}} O^{-1}\left(\mathbf{y}-\mathbf{y}^{o}\right) .
\end{aligned}
$$




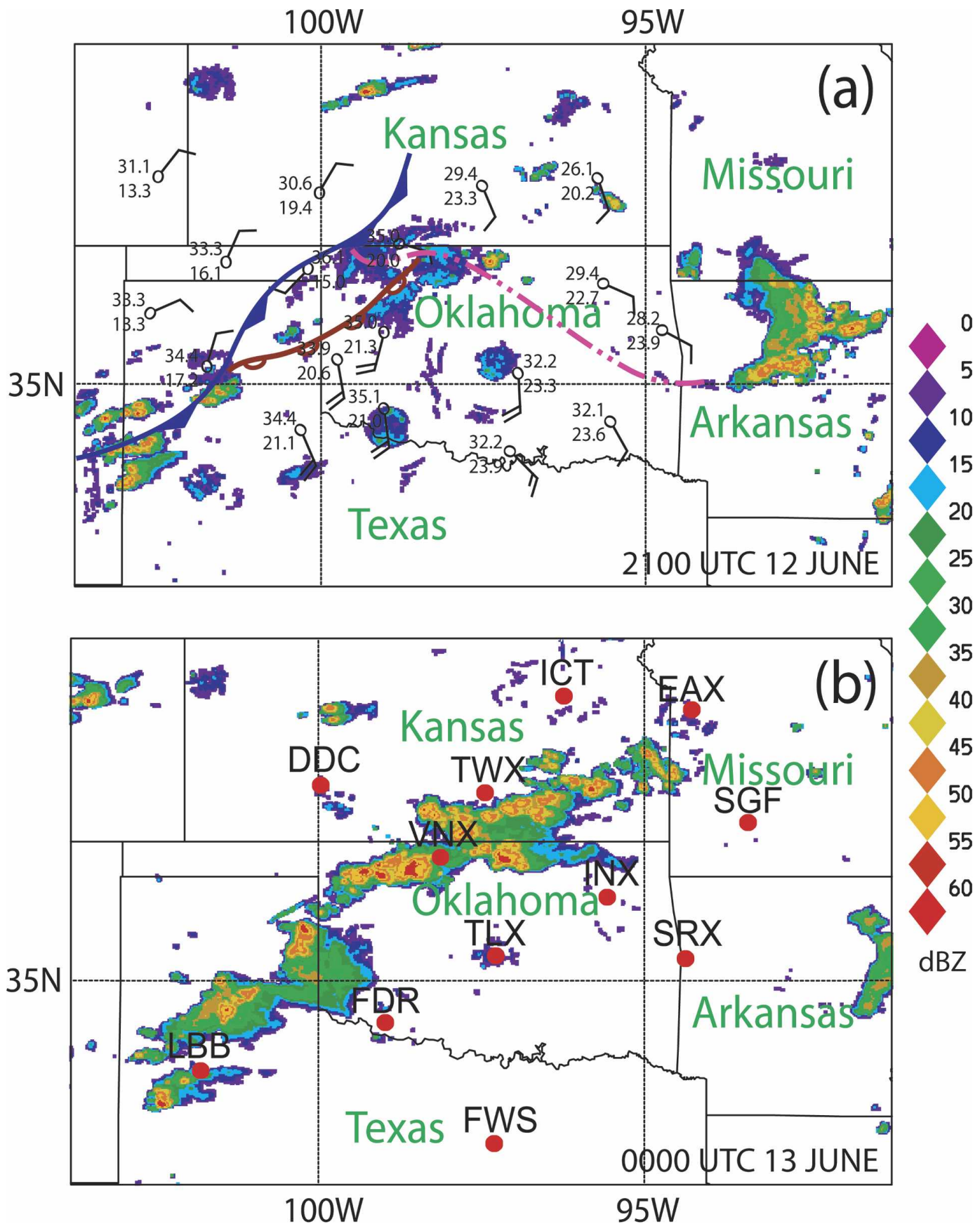

FIG. 1. Composite radar reflectivity observations (color) at (a) 2100 UTC 12 Jun and (b) 0000 UTC 13 Jun 2002. Some surface observations of temperature, dewpoint temperature, and wind speed and direction at 2100 UTC 12 Jun are plotted in (a). The cold front (blue line), dryline (brown line), and outflow boundary (pink line) at 2100 UTC 12 Jun are also depicted in (a). The 12 red dots in (b) indicate 12 WSR-88D radar stations, with their station name above the red dot. The data from the 12 WSR-88D radars are used for the Doppler radar data assimilation experiments in this paper.

The incremental approach (Courtier et al. 1994) is employed and preconditioning is achieved via a control variable transformation $\mathbf{x}-\mathbf{x}^{b}=\mathbf{U} \mathbf{v}$, where $\mathbf{v}$ is a vector of control variables. The $\mathbf{U}$ transform is well designed by a series of operations $\mathbf{U}=\mathbf{U}_{p} \mathbf{U}_{v} \mathbf{U}_{h}$ so as that $\mathbf{B}=\mathbf{U U}^{\mathrm{T}}$ (Lorenc et al. 2000). The transforms $\mathbf{U}_{p}$, $\mathbf{U}_{v}$, and $\mathbf{U}_{h}$ represent a physical transformation involving the conversion of control variables to the incre- 

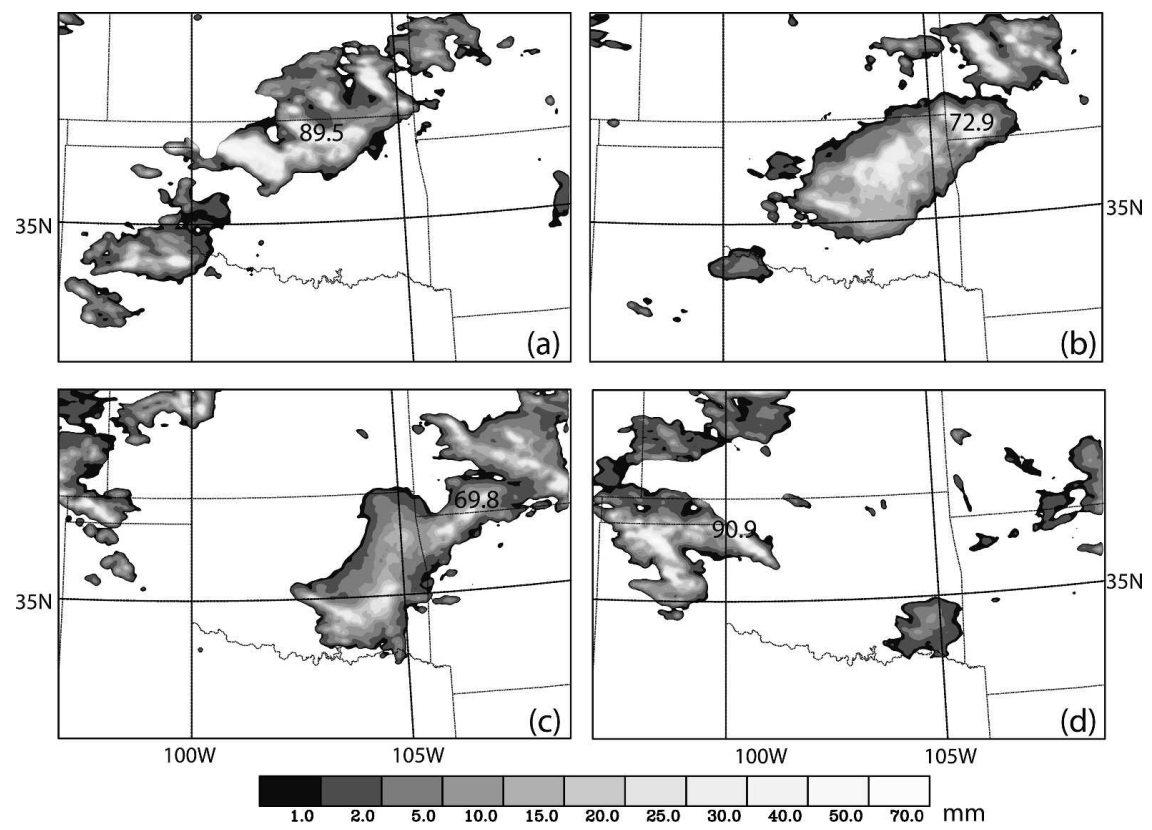

FIG. 2. The 3-h accumulated precipitations from the stage IV precipitation analysis of NCEP at (a) 0300, (b) 0600, (c) 0900, and (d) 1200 UTC 13 Jun. The maximum rainfall amount and location are shown.

ments of model variables, a vertical transformation via an empirical orthogonal function (EOF) decomposition, and a horizontal transformation by recursive filters (Hayden and Purser 1995; Purser et al. 2003), respectively. This control variable preconditioning serves to compute $\mathbf{B}^{-1}$ efficiently under an assumption that the errors among control variables are uncorrelated. The conjugate gradient method is used to minimize the incremental cost function. A method for the 3DVAR background error statistics and the control variable transformation used for the Doppler radar data assimilation will be described in the next subsection.

\section{b. Methodology for Doppler radar data assimilation}

Doppler radar data (radial velocity and reflectivity) have special features as compared with conventional observations. First of all, radial velocity contains information of vertical motion; the vertical velocity is sometimes important for the convective initiation and forecasting. The Doppler reflectivity is, in fact, a measurement of the precipitation hydrometeors (rain, snow, etc.). Nevertheless, most 3DVAR systems do not include the analysis of the vertical velocity and hydrometeor variables. Since it is difficult to assimilate vertical velocity information and reflectivity directly via a 3DVAR approach, 4DVAR is usually utilized (Sun and Crook 1997, 1998).
In WRF 3DVAR, we designed a methodology for the assimilation of Doppler radar data, including the reflectivity and vertical velocity component of radial velocity. In this method, the physical transformation of the WRF 3DVAR preconditioning was revised. A new balance equation based on the work of Richardson (1922) was introduced into the WRF 3DVAR physical transformation $\mathbf{U}_{p}$ to produce the vertical velocity increment (Xiao et al. 2005). The linearized Richardson's equation, by writing each variable in terms of a basic state (overbar) plus a small increment (prime), is

$$
\begin{aligned}
\gamma \bar{p} \frac{\partial w^{\prime}}{\partial z}= & -\gamma p^{\prime} \frac{\partial \bar{w}}{\partial z}-\gamma \bar{p} \boldsymbol{\nabla} \cdot \mathbf{v}_{h}-\gamma p^{\prime} \boldsymbol{\nabla} \cdot \overline{\mathbf{v}}_{h}-\overline{\mathbf{v}}_{h} \cdot \boldsymbol{\nabla} p^{\prime} \\
& -\overline{\mathbf{v}}_{h}^{\prime} \cdot \boldsymbol{\nabla} \bar{p}+g \int_{z}^{\infty} \boldsymbol{\nabla} \cdot\left(\overline{\rho \mathbf{v}^{\prime}}\right) d z \\
& +g \int_{z}^{\infty} \boldsymbol{\nabla} \cdot\left(\rho^{\prime} \overline{\mathbf{v}}_{h}\right) d z
\end{aligned}
$$

where $w$ is the vertical velocity, $\mathbf{v}_{h}$ is the vector of horizontal velocity (components $u$ and $v$ ), $\gamma$ the ratio of specific heat capacities of air at constant pressurevolume, $p$ the pressure, $\rho$ the density, $T$ the temperature, $c_{p}$ the specific heat capacity of air at a constant pressure, $z$ the height, and $g$ the acceleration due to gravity. The linear and adjoint of this Richardson's equation are incorporated into the 3DVAR system, 
which serve as a bridge between the 3DVAR analyses and the vertical velocity component of the Doppler radial velocity observations. Previous study (Xiao et al. 2005 ) indicated that inclusion of the vertical velocity increments in 3DVAR produced a better rainfall forecast compared with the experiment without vertical velocity increments. Even though the vertical velocity component contains only a limited portion of the radial velocity observation, its influence is important for short-range rainfall forecast. Vertical velocity is one of the crucial dynamical variables to be targeted for analysis for convective systems.

To assimilate the Doppler reflectivity, we used the total water mixing ratio $q_{t}$ as a control variable, and introduced a warm rain process to partition the moisture and water hydrometeor increments in the physical transformation $\mathbf{U}_{p}$ (Xiao et al. 2007). The control variable vector $\mathbf{v}$ contains components of the streamfunction, velocity potential, unbalanced pressure, and total water mixing ratio. The WRF 3DVAR background error statistics were estimated using the ensemble method of Fisher (1999). Since cloud hydrometeor variables are not continuously distributed, they are not appropriate choices in the control variables to perform background error statistics. Therefore, we introduced the total water mixing ratio $q_{t}$ as a control variable and calculated the background error statistics using $q_{t}$. The warm rain process includes condensation of water vapor into cloud $\left(P_{\mathrm{CON}}\right)$, accretion of cloud by rain $\left(P_{\mathrm{RA}}\right)$, automatic conversion of cloud to rain $\left(P_{\mathrm{RC}}\right)$, and evaporation of rain to water vapor $\left(P_{\mathrm{RE}}\right)$. The tangent linear and its adjoint of the scheme are developed and incorporated into the 3DVAR system. Although the control variable is $q_{t}$, the increments of water vapor mixing ratio $q_{v}$, cloud water mixing ratio $q_{c}$, and rainwater mixing ratio $q_{r}$ are produced through the partitioning procedure during the 3DVAR analysis. The warm rain parameterization builds a relationship between rainwater, cloud water, moisture, and temperature. Details of the warm rain scheme and its implementation procedure are described in Xiao et al. (2007). When rainwater information (from reflectivity) enters into the minimization iteration procedure, the forward warm rain process and its backward adjoint distribute this information to the increments of other variables (under the constraint of the warm rain scheme). Once the 3DVAR system produces the $q_{c}$ and $q_{r}$ increments, the assimilation of reflectivity is straightforward.

The observation operator for the Doppler radial velocity is

$$
\mathbf{V}_{r}=u \frac{x-x_{i}}{r_{i}}+v \frac{y-y_{i}}{r_{i}}+\left(w-\mathbf{v}_{t}\right) \frac{z-z_{i}}{r_{i}}
$$

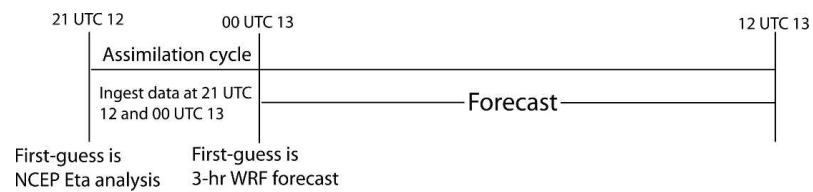

FIG. 3. Schematic diagram of the experimental design illustrating the data assimilation cycle and forecast.

where $(u, v, w)$ are the wind components, $(x, y, z)$ are the radar location, $\left(x_{i}, y_{i}, z_{i}\right)$ are the location of the radar observation, $r_{i}$ is the distance between the radar and the observation, and $\mathbf{v}_{T}$ is the terminal velocity. Following the algorithm of Sun and Crook (1998),

$$
\mathbf{v}_{T}=5.40 a \cdot q_{r}^{0.125} .
$$

The quantity $a$ is a correction factor defined by

$$
a=\left(p_{0} / \bar{p}\right)^{0.4},
$$

where $\bar{p}$ is the base-state pressure and $p_{0}$ is the pressure at the ground.

The observation operator for the Doppler radar reflectivity is (Sun and Crook 1997)

$$
Z=43.1+17.5 \log \left(\rho q_{r}\right),
$$

where $Z$ is the reflectivity in the unit of $\mathrm{dB} Z$ and $q_{r}$ is the rainwater mixing ratio.

\section{Experimental design}

Based on the convective initiation, evolution, and decay process of the IHOP_2002 squall line described in section 2, we conducted a data assimilation from 2100 UTC 12 June to 0000 UTC 13 June, and a 12-h numerical forecast from 0000 to 1200 UTC 13 June 2002 (Fig. 3). The WRF 3DVAR with data cycling was used for the assimilation, and the WRF-ARW (Skamarock et al. 2005) was used for the 12-h forecast. All experiments were conducted over a grid mesh of $400 \times 400 \mathrm{~km}^{2}$ with grid spacing of $4 \mathrm{~km}$; this covers $1600 \times 1600 \mathrm{~km}^{2}$ over the central United States, including the Great Plains (Fig. 4). In the vertical, there are $27 \eta$ layers $(1,0.99$, $0.978,0.964,0.946,0.922,0.894,0.86,0.817,0.766,0.707$, $0.644,0.576,0.507,0.444,0.38,0.324,0.273,0.228,0.188$ $0.15,0.121,0.093,0.069,0.048,0.029,0.014,0)$, and the model top is $50 \mathrm{hPa}$. The IHOP_2002 region is contained within the eastern half of the model domain. The 12 WSR-88D radar stations are shown in Fig. 4. The rectangular thick box indicates the region in which we perform our QPF skill verification in the following sections.

Two analyses are conducted at 2100 UTC 12 June 


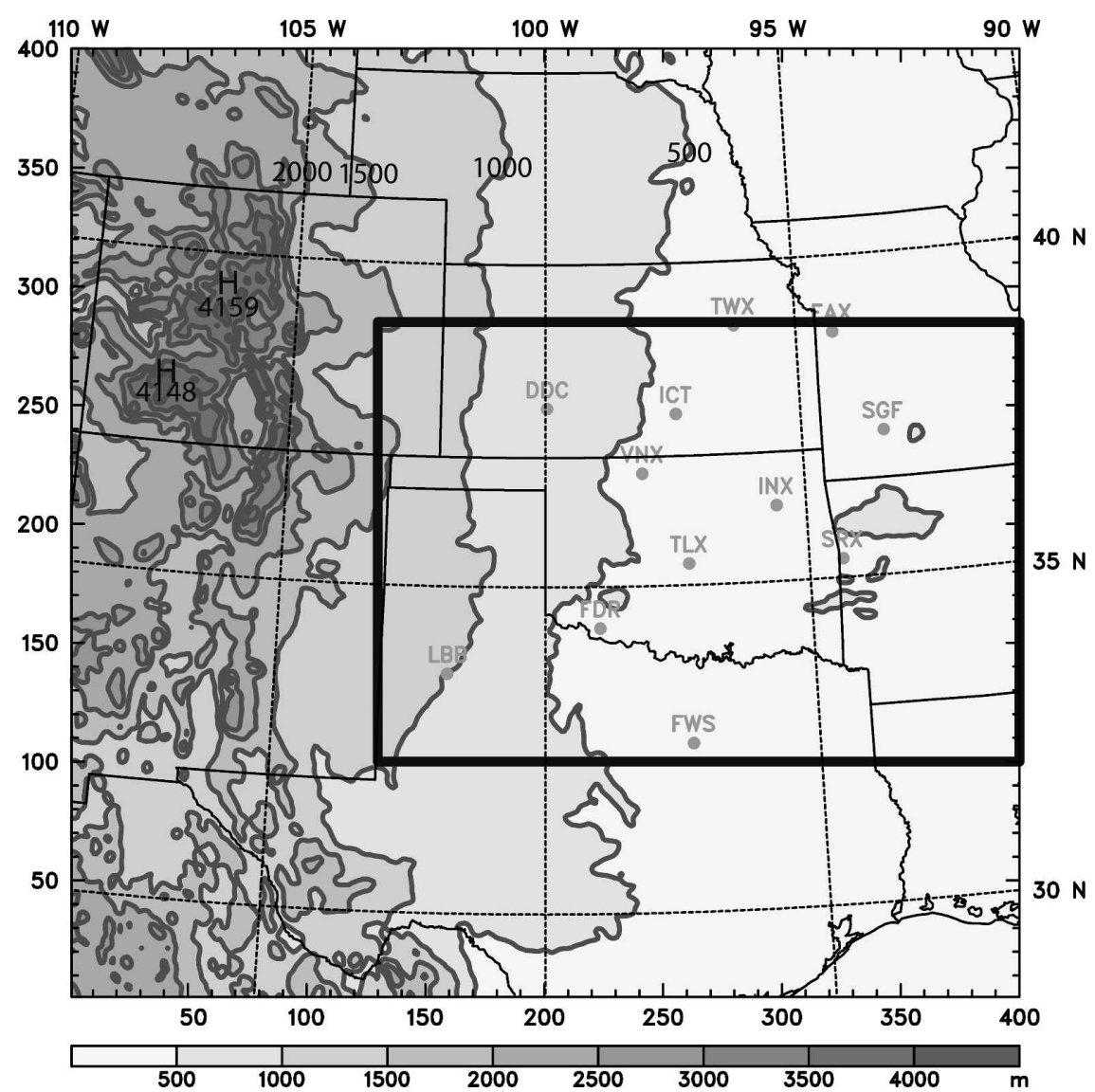

FIG. 4. The 4-km resolution model domain $(400 \times 400)$ with shaded terrain elevation contours. The thick rectangular box indicates the region of rainfall distribution in Fig. 2 and the rainfall verification in section 6 . Also shown are the 12 WSR-88D radar stations used in the data assimilation experiments.

and 0000 UTC 13 June 2002. The interpolated Eta Model analysis at 2100 UTC 12 June is used as the first guess for the 3DVAR (cold start). The 3-h ARW forecast ending at 0000 UTC 13 June serves as the first guess for the second 3DVAR analysis (3-h cycling; Fig. 3). In addition to the Doppler radar data, conventional observations (including radiosonde and surface data) at 2100 UTC 12 June and 0000 UTC 13 June are also included in the 3DVAR 3-h cycling. Experiments with more frequent (every $1 \mathrm{~h}$ or $30 \mathrm{~min}$ ) data assimilation cycling for this case indicated that the rainfall verification did not beat the 3-h cycling experiment, and the results are not shown in this paper. We speculate that the major characteristics of the squall line and its rainfall could not be spun up in $1 \mathrm{~h}$ or $30 \mathrm{~min}$ from previous 3DVAR analyses.

Besides the first-guess $\mathbf{x}^{b}$ and observations $\mathbf{y}^{o}$, another important input for WRF 3DVAR is the background error covariance matrix B. To calculate the background error statistics, we carried out 30 forecasts using ARW with different initial conditions at 0000 UTC 13 June. The 30 members of the initial conditions were obtained by 3DVAR with different combinations of the observations and first guesses. The differences between each forecast and its ensemble mean are taken as background errors. The background error covariance was then calculated via an ensemble method (Fisher 1999; Lee et al. 2006). An empirical factor of 0.65 was applied to the calculated length scales in this study.

All of the ARW physics in our experiments are the same, which include the rapid radiative transfer model (RRTM) based on Mlawer et al. (1997) for longwave radiation, the Dudhia (1989) shortwave radiation scheme, the Medium-Range Forecast (MRF) model PBL scheme described by Hong and Pan (1996), and the WRF Single-Moment 6-Class Microphysics (WSM6) scheme's microphysics, which is similar to that used by Lin et al. (1983). No cumulus parameterization scheme is used for the 4-km-resolution model design. 
TABLE 1. Summary of experiments.

\begin{tabular}{ll}
\hline \hline Expt & \multicolumn{1}{c}{ WRF 3DVAR setup } \\
\hline CTRL & Two-time conventional data assimilations; no radar data included \\
RVZ1 & Same as CTRL but radial velocity and reflectivity data from 12 radar stations at 0000 UTC 13 Jun are included \\
RVZ2 & Same as CTRL but radial velocity and reflectivity data from 12 radar stations at 2100 UTC 12 Jun and 0000 UTC 13 Jun \\
& are included \\
RV1 & Same as RVZ1 but with radial velocity data only \\
RZ1 & Same as RVZ1 but with reflectivity data only \\
RV2 & Same as RVZ2 but with radial velocity data only \\
RZ2 & Same as RVZ2 but with reflectivity data only \\
VNX & Same as RVZ2, but with radial velocity and reflectivity from only one Doppler radar (VNX, Vance AFB; shown in \\
& Fig. 1b) \\
\hline
\end{tabular}

The 12-h ARW model forecast begins at 0000 UTC 13 June from the 3DVAR analyses (Fig. 3).

A number of assimilation and forecast experiments were conducted to examine the QPF skill and sensitivity of the forecast with respect to various changes in the Doppler radar data assimilation strategies (Table 1). The Doppler radar data assimilation sensitivity tests include 1) the impacts of radial velocity, or reflectivity, or both combined; 2) single-Doppler radar data versus multiple-Doppler radar data experiments; and 3) onetime radar data assimilation versus 3DVAR cycling of multiple-time radar observations. All of the experiments are summarized in Table 1.

\section{Model initial conditions with Doppler radar data assimilation}

\section{a. Single-observation test}

The single-observation test is an efficient way to determine how the observed information spreads to its vicinity via the established correlations among 3DVAR variables. Using the CTRL forecast at 0000 UTC 13 June 2002 as the first guess, we conducted two tests by assimilating a single-point radial velocity datum and a single-point reflectivity datum, respectively. The single radial velocity or reflectivity data point is at $\left(36.790^{\circ} \mathrm{N}\right.$, $-97.093^{\circ} \mathrm{W} ; 3139.9 \mathrm{~m}$ ) for the VNX Doppler radar (located at $\left.36.741^{\circ} \mathrm{N},-98.128^{\circ} \mathrm{W} ; 378 \mathrm{~m}\right)$. The innovations (observation minus background, $O-B$ ) of the single radial velocity and single reflectivity data points were assigned to $1 \mathrm{~m} \mathrm{~s}^{-1}$ and $1 \mathrm{dBZ}$, respectively.

With a $1 \mathrm{~m} \mathrm{~s}^{-1}$ innovation of the assigned single radial velocity, the 3DVAR analysis deviation (observation minus analysis, $O-A$ ) reduces to $0.3805 \mathrm{~m} \mathrm{~s}^{-1}$. Figure 5 shows the WRF 3DVAR analysis increment in response to the single radial velocity at $3139.9 \mathrm{~m}$ (the same vertical height as with the single observation). The $u$ and $v$ increments (Figs. 5a and 5b) indicate that a cyclonic circulation is produced on the north side of the radar data, and an anticyclonic circulation is produced on the south side of the radar data. The vertical velocity increment is created (Fig. 5c), but with a much smaller length scale than for the horizontal wind. The temperature increment response to the radial velocity assimilation is small, but its length scale is larger than that of the wind increments. Note that these patterns are mainly from the large-scale response. How to set up mesoscale background error statistics and mesoscale balance is still a challenge. However, these correlation structures should be kept to a large extent in mesoscale system. In addition, we noticed that the influence radius of observational innovation is large considering the squall-line case and the radar data density. We will study how to tune the background error statistics in the future. With the tuned background error statistics, further improvement in mesoscale prediction should be expected.

Figure 6 shows the WRF 3DVAR analysis increment responses to the assigned single reflectivity observation at $3139.9 \mathrm{~m}$. First of all, the rainwater mixing ratio $\left(q_{r}\right)$ has positive analysis increments (Fig. 6a) in response to the assigned 1-dBZ innovation. The WRF 3DVAR also produces increments of other variables due to its multivariate nature. The increment distributions of the cloud water mixing ratio $q_{c}$ (Fig. 6b), water vapor mixing ratio $q_{v}$ (Fig. $6 \mathrm{c}$ ), and temperature (Fig. 6d) depend on the microphysical process and the first-guess state. The redistribution of hydrometeors in the water cycle causes changes of temperature through condensation and evaporation. Figure $6 \mathrm{~d}$ indicates that more condensational heating occurs from water vapor to cloud water than for evaporational cooling from rainwater to water vapor; thus, the temperature increments present a positive value in this case (Fig. 6d). Due to the WRF 3DVAR's multivariate nature, the wind increments are also created in response to the $1-\mathrm{dB} Z$ reflectivity innovation (through the forcing of temperature increments; figures omitted). A distinct pattern in the hydrometeor 


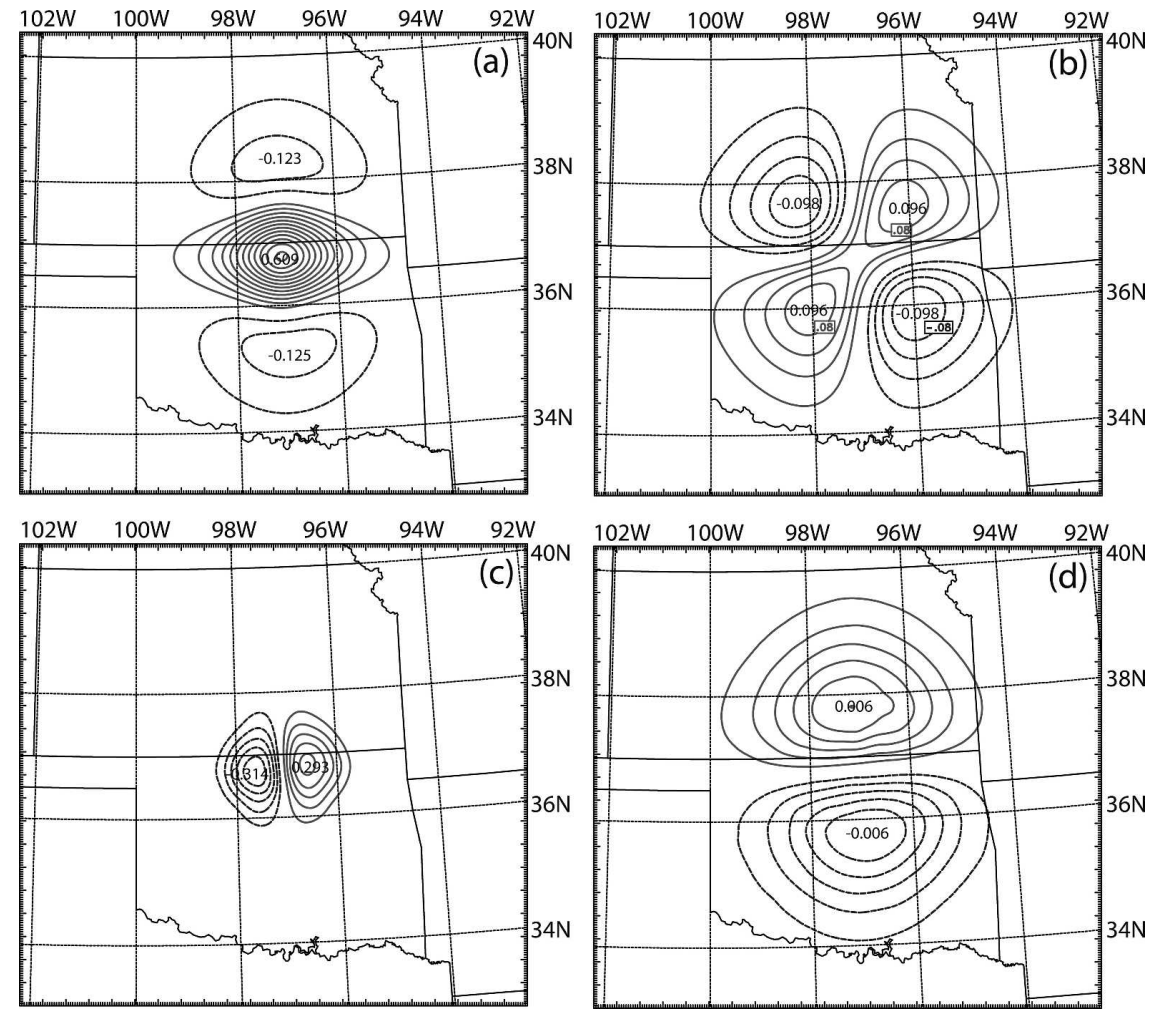

FIG. 5. The WRF 3DVAR analysis increment response at $3139.9 \mathrm{~m}$ to a single observation of radial velocity with $1 \mathrm{~m} \mathrm{~s}^{-1}$ innovation at $36.790^{\circ} \mathrm{N},-97.093^{\circ} \mathrm{W}(3139.9 \mathrm{~m})$ for the VNX Doppler radar (located at $36.741^{\circ} \mathrm{N},-98.128^{\circ} \mathrm{W} ; 378 \mathrm{~m}$ ): (a) $u$, (b) $v$, (c) $w$, and (d) $T$. [Contour intervals (CIs) are $0.05,0.02$, and $0.05 \mathrm{~m} \mathrm{~s}^{-1}$, and $0.001 \mathrm{~K}$, respectively; negative isolines are dashed, and the zero isoline is omitted.]

analysis increments is its asymmetric, anisotropic distribution. Although an isotropic recursive filter is applied to the WRF 3DVAR background error covariance of the preconditioned control variables, the nonlinear hydrometeor partitioning scheme causes the asymmetric, anisotropic incremental feature. The microphysics scheme in hydrometeor partitioning is very nonlinear, and its linear scheme is background dependant. Because the background cloud water $\left(q_{c}\right)$ and rainwater $\left(q_{r}\right)$ are not continuous and their spatial variations are not homogeneous, the hydrometeor increments calculated by the microphysics parameterization show the anisotropic pattern. The inclusion of cloud hydrometeor increments in the WRF 3DVAR multivariate correlation structure is important for Doppler reflectivity assimilation.

\section{b. Analyses with one-time Doppler radar data assimilation}

The experiments RV1, RZ1, RVZ1, and CTRL have the same first-guess fields. RV1, RZ1, and RVZ1 are one-time Doppler radar data experiments. Figure 7 shows the $850-\mathrm{hPa}$ wind difference vector and velocity difference from CTRL for RV1 (panel a) and RVZ1 (panel b), and the 850-hPa wind barb and 500-hPa vertical velocity difference for RV1 (panel c) and RVZ1 (panel d). The assimilation of solely Doppler reflectivity caused marginal differences in the wind and vertical velocity fields between RZ1 and CTRL (thus, the figures are omitted). With assimilation of radial winds, both RV1 and RVZ1 produce additional lower-level convergences in the wind increments along the dryline in Texas compared when with CTRL (Figs. 7a and 7b). The cyclonic wind shear along the Kansas-Oklahoma border and near the triple point is increased in RV1 and RVZ1 (Figs. 7a and 7b). The midlevel vertical velocity at $500 \mathrm{hPa}$ indicates increased updraft behind and downdraft in front of the dryline compared with CTRL because of the assimilation of radial velocities in RV1 and RVZ1 (Figs. 7c and 7d). The 850-hPa wind barbs in Figs. $7 \mathrm{c}$ and $7 \mathrm{~d}$ also clearly show the wind shear along the dryline.

Figure 8 shows the $950-\mathrm{hPa}$ moisture analysis and its difference from CTRL (Figs. $8 \mathrm{a}$ and $8 \mathrm{~b}$ ) and the 

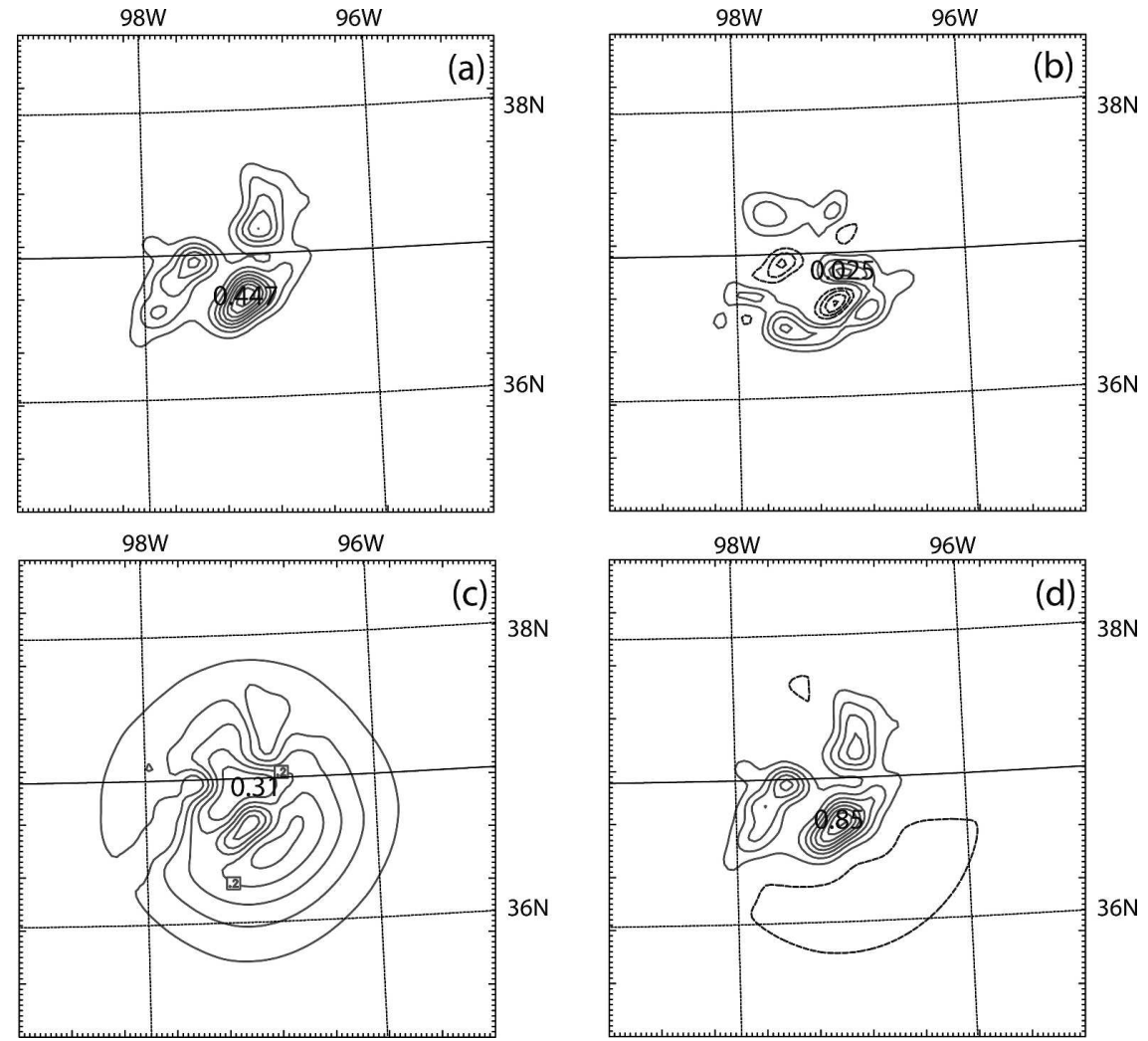

FIG. 6. The WRF 3DVAR analysis increment response at $3139.9 \mathrm{~m}$ to a single reflectivity observation with $1-\mathrm{dBZ}$ innovation at $\left(36.790^{\circ} \mathrm{N},-97.093^{\circ} \mathrm{W} ; 3139.9 \mathrm{~m}\right)$ for the VNX Doppler radar (located at $36.741^{\circ} \mathrm{N},-98.128^{\circ} \mathrm{W} ; 378 \mathrm{~m}$ ): (a) $q_{r}$, (b) $q_{c}$, (c) $q_{v}$, and (d) $T$. (CIs are 0.05 , 0.005 , and $0.05 \mathrm{~g} \mathrm{~kg}^{-1}$, and $0.1 \mathrm{~K}$, respectively; negative isolines are dashed and the zero isoline is omitted.)

700-hPa analyzed reflectivity and the rainwater mixing ratio difference from CTRL (Figs. 8c and 8d) for experiments RZ1 and RVZ1. The dryline feature is clearly shown in the gradient of the water vapor mixing ratio for both experiments RZ1 and RVZ1 (Figs. 8a and $8 \mathrm{~b}$ ). The southwest-to-northeast-oriented high moisture gradient line extending through the Texas Panhandle defines the dryline in Fig. 8. The analyses with and without radial velocity both decrease the moisture near the central Oklahoma-Kansas border. In the analyzed reflectivity fields (Figs. $8 \mathrm{c}$ and $8 \mathrm{~d}$ ), the squall line is broken in west Oklahoma near the Oklahoma-Texas border, and in north-central Oklahoma near the Oklahoma-Kansas border. The rainwater mixing ratio shows a negative difference from the CTRL experiment in both areas (contours in Figs. 8c and 8d). The maximum decrease of the rainwater mixing ratio in both areas is over $3 \mathrm{~g} \mathrm{~kg}^{-1}$. These negative differences in rainwater mixing ratio cause less convection than CTRL in both areas.

Assimilation of the radial velocity only has a large impact on the wind and vertical velocity analysis, and its impact on moisture and hydrometeor analysis is secondary. On the other hand, assimilation of reflectivity only has a great impact on the moisture and hydrometeor analysis, and its impact on the wind or vertical velocity analysis is secondary. When both the radial velocity and reflectivity are assimilated, we obtained analyses that have adjustments in both the dynamical and thermodynamical fields that are consistent with the WRF 3DVAR balance constraint and background error correlations. In addition, the $3 \mathrm{DVAR}$ analysis fits to the assimilated observations due to its minimization procedure. We will evaluate the impact of Doppler radar data assimilation in sections 6 and 7 .

\section{c. Analyses with two-time Doppler radar data assimilation}

With two-time Doppler radar data assimilations using the WRF 3DVAR cycling mode, the analysis at 0000 UTC 13 June combines the information from both times; the impact of Doppler radar data at 2100 UTC 12 June propagates to the background of the 0000 UTC 13 

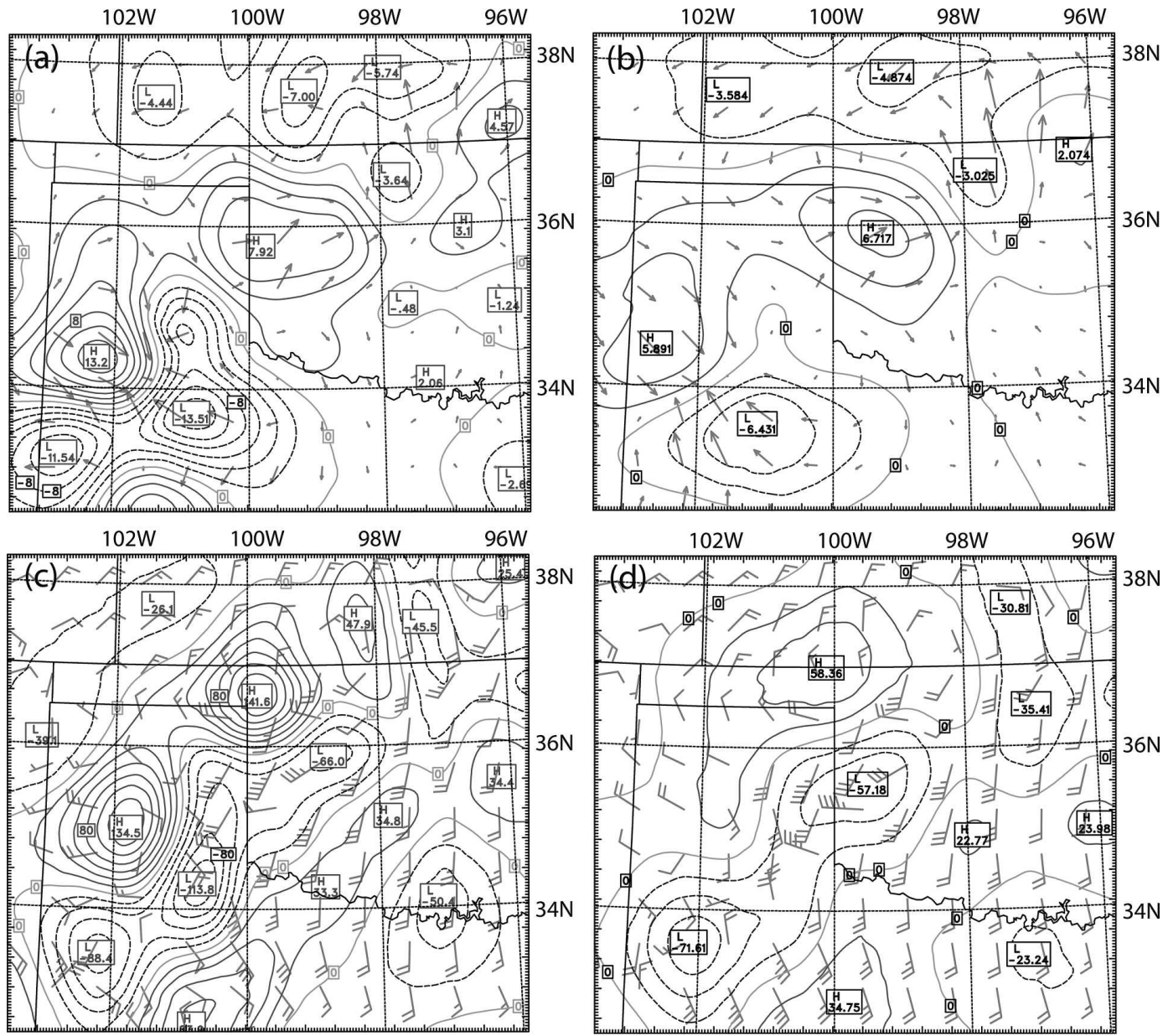

FIG. 7. Analyzed 850-hPa wind difference vector (arrows) and velocity difference (CI of $2 \mathrm{~m} \mathrm{~s}^{-1}$; negative lines dashed) from CTRL for (a) RV1 and (b) RVZ1; and the 850-hPa wind barb (full bar represents $5 \mathrm{~m} \mathrm{~s}^{-1}$ ) and 500-hPa vertical velocity difference (CI of $20 \mathrm{~cm} \mathrm{~s}^{-1}$, negative lines dashed) from CTRL for (c) RV1 and (d) RVZ1 at 0000 UTC 13 Jun.

June analysis via ARW model integration. In this case, the first guesses of CTRL, RV2, RZ2, and RVZ2 at 0000 UTC 13 June are different.

It is notable that the assimilation of both the radial velocity and reflectivity data in the 3DVAR assimilation cycles produce several special features in the convection and hydrometeor distribution. One of the distinct differences between the RVZ2 experiment and CTRL is in the vertical velocity analysis (Figs. 9a and 9b). When no radar observations are assimilated, the maximum upward vertical velocity is distributed along a straight line (Fig. 9a). A strong squall line is produced due to the upward vertical motions along the line, as shown in the reflectivity field at $700 \mathrm{hPa}$ (Fig. 9c). However, when the two-time Doppler radial velocity and reflectivity data are cycled in the analysis, the line structure in the vertical velocity field is significantly altered (Fig. 9b). In general, the upward motion along the squall line is decreased compared to that in CTRL. Further examination reveals that four maxima of upward motion (denoted by A, B, C, and D) correspond to the maxima of increased rainwater (Fig. 9d). Comparing Figs. 9c and 9d, it is clearly seen that the convective line in RVZ2 is broken and displays a more cellular structure as a result of the radar data assimilation. The analyses of these individual convective cells agree quite well with the observations (Fig. 1b).

As a further discussion, it should be noted that RVZ2 deletes some spurious convections in CTRL that do not exist in the observations (Fig. 1b). For example, the rainwater mixing ratio along the squall line is greatly reduced (Fig. 9d) from CTRL (Fig. 9c). The contour plot in Fig. 9d indicates that negative differences in rainwater mixing ratio are produced in RVZ2. This change causes the squall line to retreat back to the west a little in RVZ2. Since the general pattern of reflectivity 

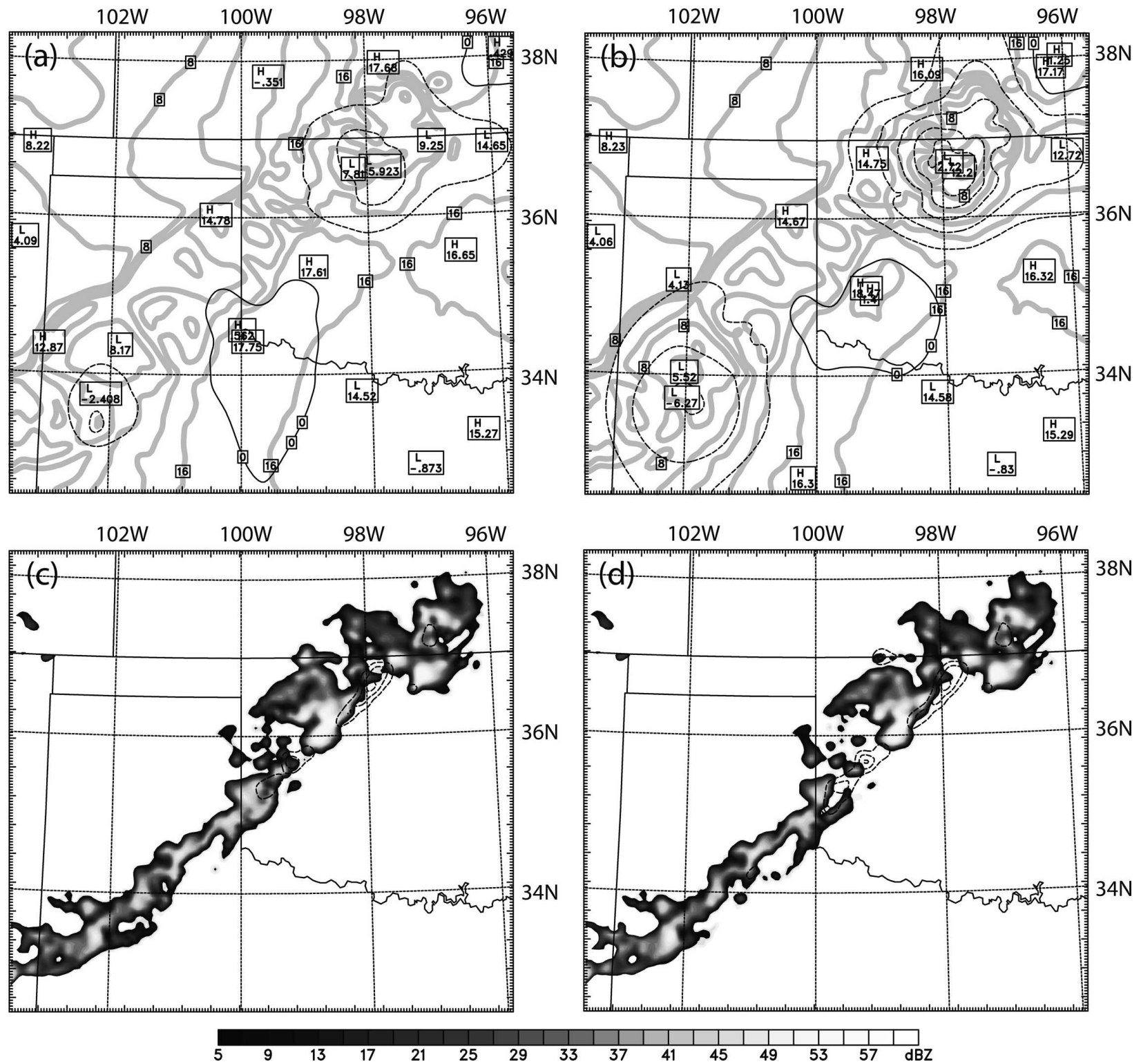

FIG. 8. Analyzed 950-hPa water vapor mixing ratio (gray thick isolines with CI of $2 \mathrm{~g} \mathrm{~kg}^{-1}$ ) and its difference from CTRL (thin isolines with CI of $2 \mathrm{~g} \mathrm{~kg}^{-1}$; negative lines dashed) by (a) RZ1 and (b) RVZ1; and the 700-hPa reflectivity (dBZ, with grayscales below the bottom panel) and difference in rainwater mixing ratio from CTRL at $700 \mathrm{hPa}$ (CI of $1 \mathrm{~g} \mathrm{~kg}^{-1}$, negative lines dashed) by (c) RZ1 and (d) RVZ1 at 0000 UTC 13 Jun.

in RZ2 (figure omitted) is similar to that in RVZ2, we believe that the improvement of the squall-line hydrometer field is mainly from the radar reflectivity assimilation, similar to the one-time radar data assimilation experiments.

Figure 10 shows the $850-\mathrm{hPa}$ wind difference vector and velocity difference between the Doppler velocity assimilation experiments (RV2 and RVZ2) and CTRL. The patterns of both analyses are similar (Figs. 10a and $10 \mathrm{~b}$ ); the assimilation of the radial velocity in 3DVAR cycling mode produces a southwest-to-northeast- oriented wind increase zone along the dryline. The wind difference vector clearly shows a convergence line in front of the dryline. In the area near the OklahomaKansas border, there is a cyclonic circulation that is evident in the wind difference field, similar to the RV1 and RVZ1 analyses (Figs. 7a and 7b). The strength of the cyclonic circulation in RV2 and RVZ2 compared with CTRL is favorable to the convective development in this area. The observations show that the convection in this area grows, resulting in the squall line near the Kansas-Oklahoma border (Fig. 1). 

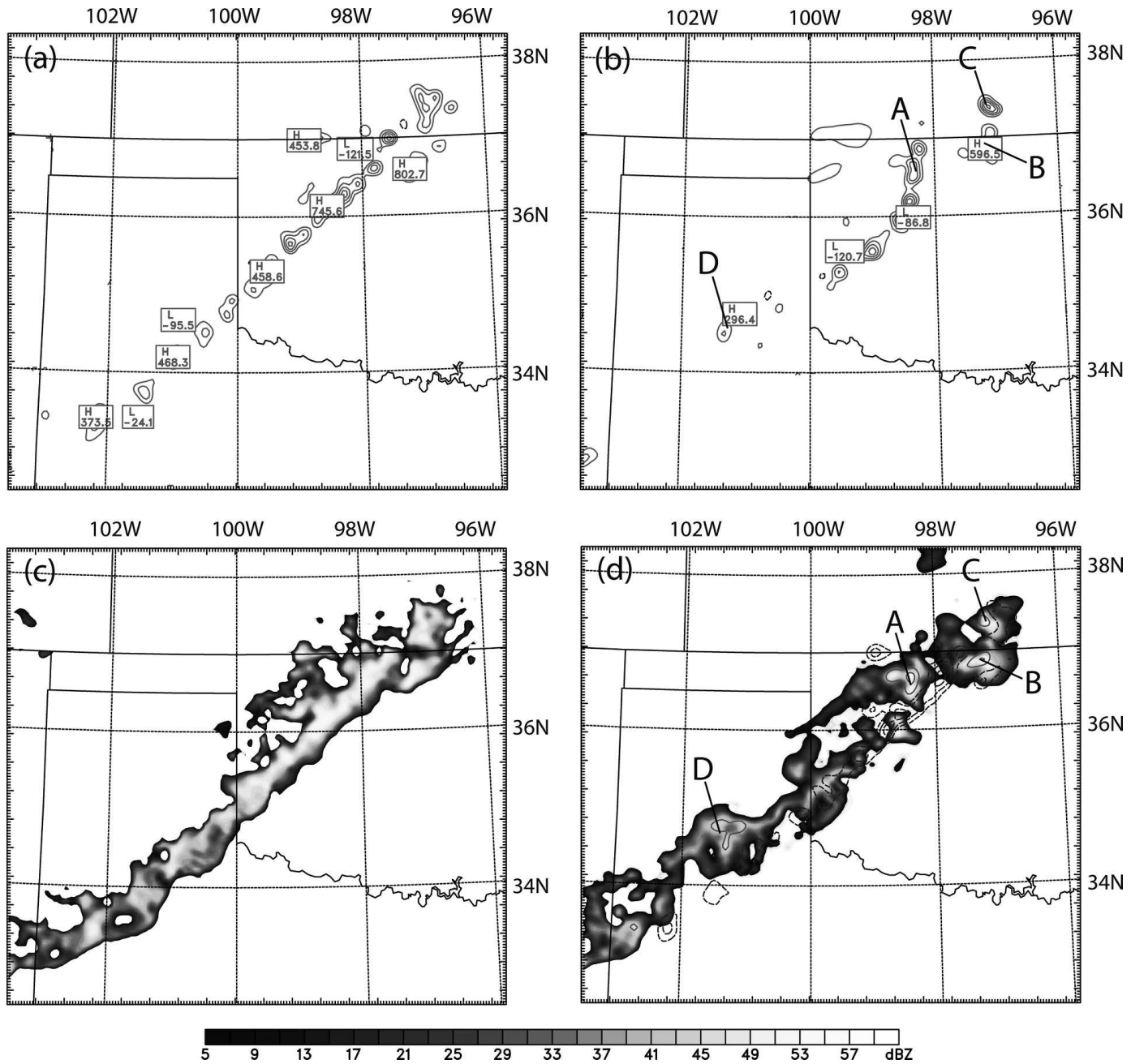

FIG. 9. Analyzed $500-\mathrm{hPa}$ vertical velocity (thin isolines with $\mathrm{CI}$ of $100 \mathrm{~cm} \mathrm{~s}^{-1}$; negative lines dashed) by (a) CTRL and (b) RVZ2, and the 700-hPa reflectivity (dBZ, with grayscale on the bottom) and difference in rainwater mixing ratio from CTRL (CI of $1 \mathrm{~g} \mathrm{~kg}^{-1}$; negative lines dashed and zero lines omitted) by (c) CTRL and (d) RVZ2 at 0000 UTC 13 Jun. The four convective cells A, B, C, and D are shown in (b) and (d).

Figure 11 shows the 850-hPa water vapor mixing ratio $q_{v}$ and its difference from CTRL in RZ2 and RVZ2 at 0000 UTC 13 June 2002. We notice that the assimilation of the reflectivity data (RZ2 and RVZ2) increases the low-level moisture in front of the dryline compared to CTRL, resulting in the increased moisture gradient. In the area near the Oklahoma-Kansas border, there is a moisture decrease in RZ2 and RVZ2 compared with CTRL. The drying area extended farther east in RVZ2 than RZ2. The moistening region corresponds to the convective cell A (Fig. 9d), which does not exist in CTRL (Fig. 9a). The drying region is associated with the reduction of the reflectivity in the area between the convective cells A, B, and C. The results from the experiments RVZ2, RV2, and RZ2 indicate that the cycling of Doppler radar data produces a much more realistic pattern in the analysis.

\section{Evaluation of the ARW QPF skill}

To evaluate the QPF skills of the designed experiments, the threat score (TS) and bias of precipitation forecast in each experiment, verified against the 3-h accumulated precipitation from the NCEP stage IV precipitation analysis, are calculated. We evaluated the impact of different assimilation strategies on the QPF of this squall-line case, based on the calculated TSs and bias scores in the following subsections.

\section{a. Radar data cycling versus no cycling}

Figure 12 shows TSs and bias scores of the three experiments (CTRL, RVZ1, and RVZ2) with thresholds of 1,5 , and $10 \mathrm{~mm}$, respectively. For this squallline case, the main concern is the QPF over the Oklahoma-Kansas region between 0000 and 0900 UTC 13 

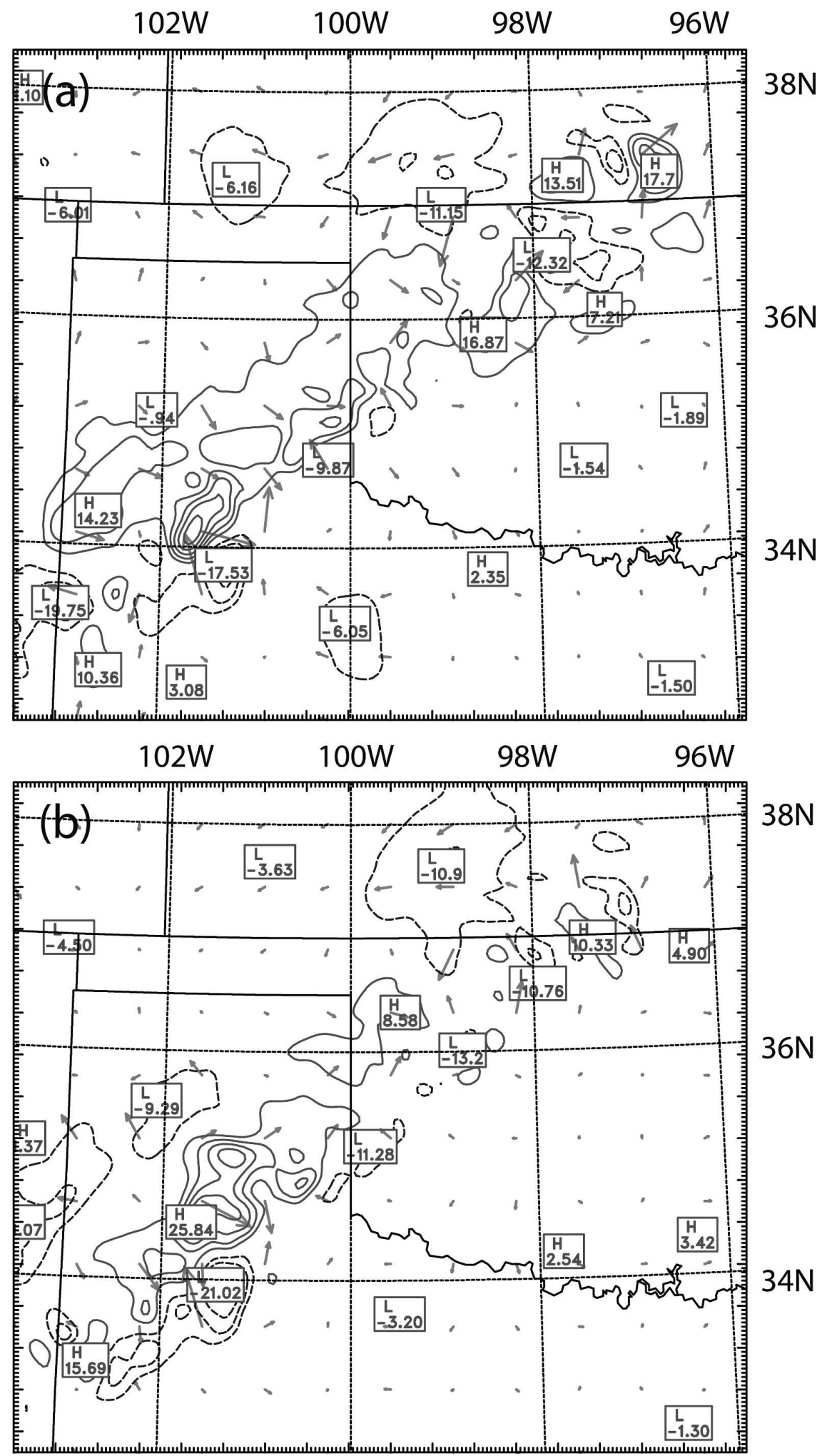

FIG. 10. Difference of 850-hPa wind velocity (CI of $5 \mathrm{~m} \mathrm{~s}^{-1}$; negative lines dashed) and wind difference vectors (arrows) from CTRL for (a) RV2 and (b) RVZ2 at 0000 UTC 13 Jun. 


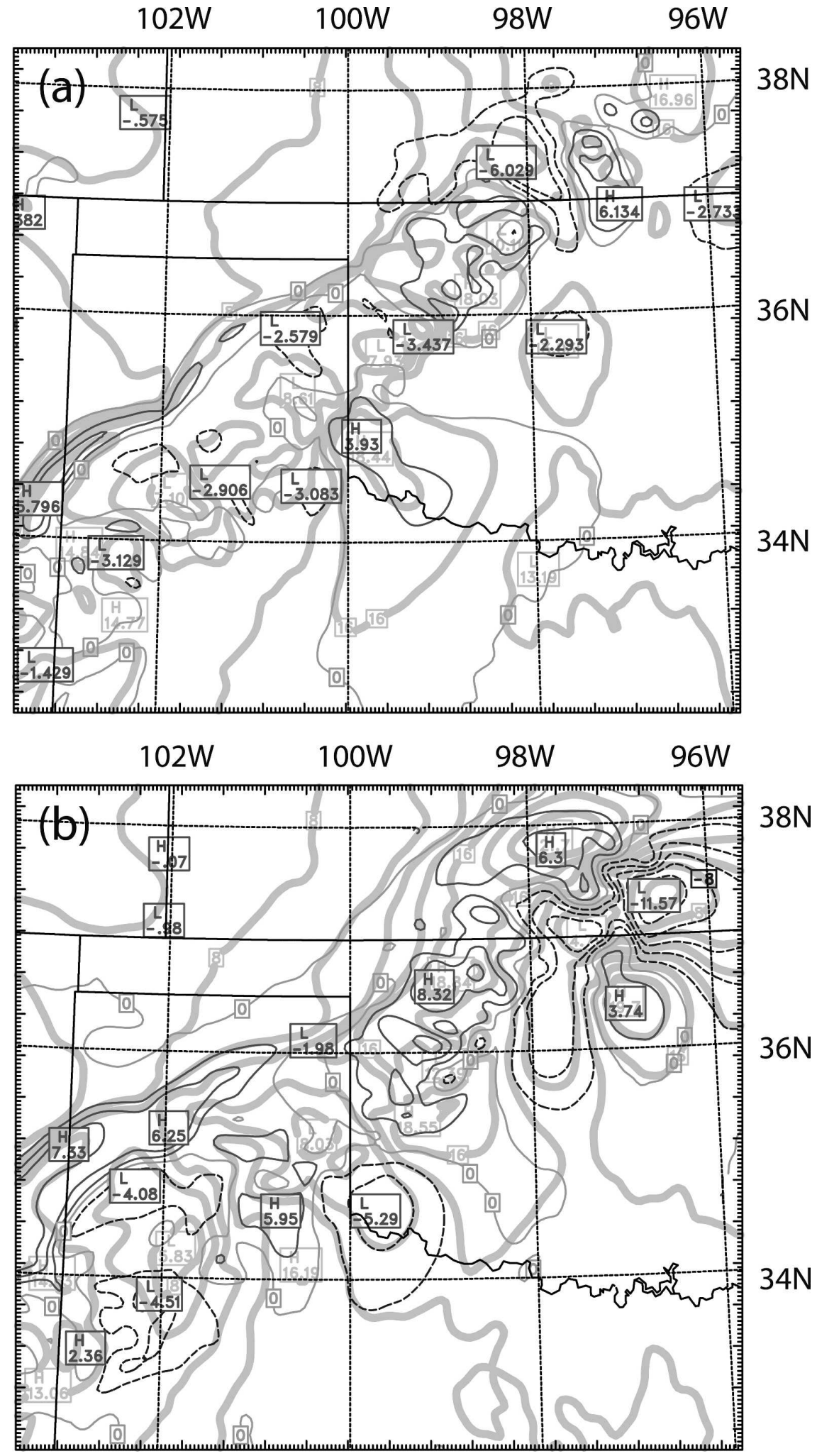

FIG. 11. Analyzed 850-hPa water vapor mixing ratio $q_{v}$ (thick gray isolines with $\mathrm{CI}$ of $2 \mathrm{~g}$ $\mathrm{kg}^{-1}$ ) and its difference from CTRL (thin isolines with CI of $2 \mathrm{~g} \mathrm{~kg}^{-1}$; negative lines dashed) by (a) RZ2 and (b) RVZ2 at 0000 UTC 13 Jun. 
(a) Threshold $=1 \mathrm{~mm}$

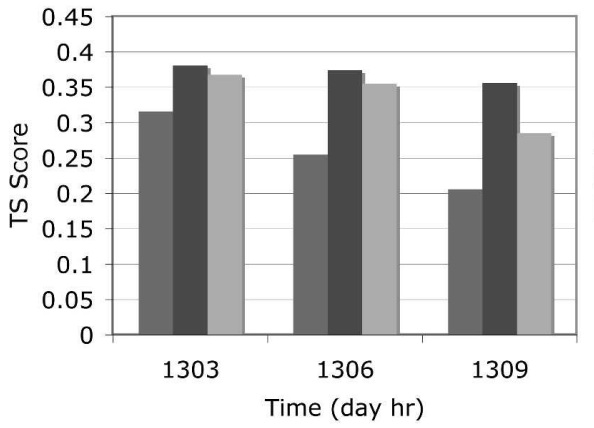

(b) Threshold $=5 \mathrm{~mm}$

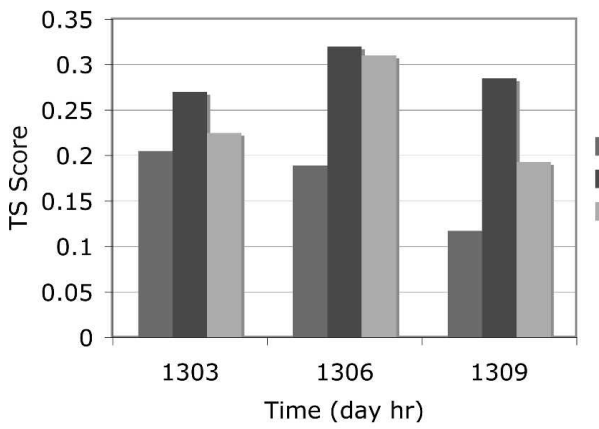

(c) Threshold $=10 \mathrm{~mm}$

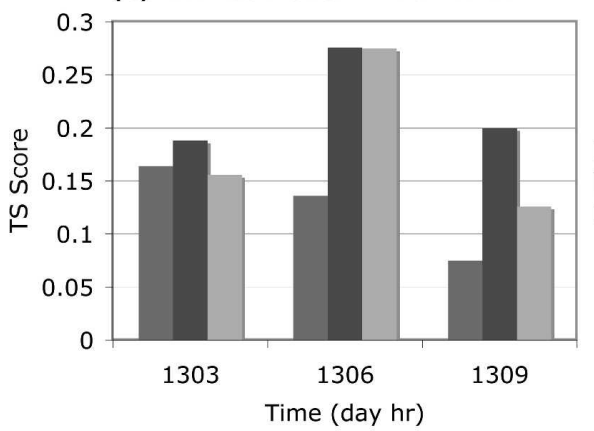

(d) Threshold $=1 \mathrm{~mm}$

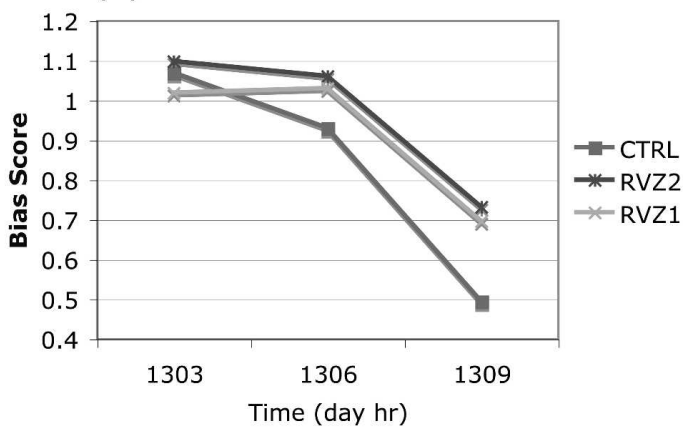

(e) Threshold $=5 \mathrm{~mm}$

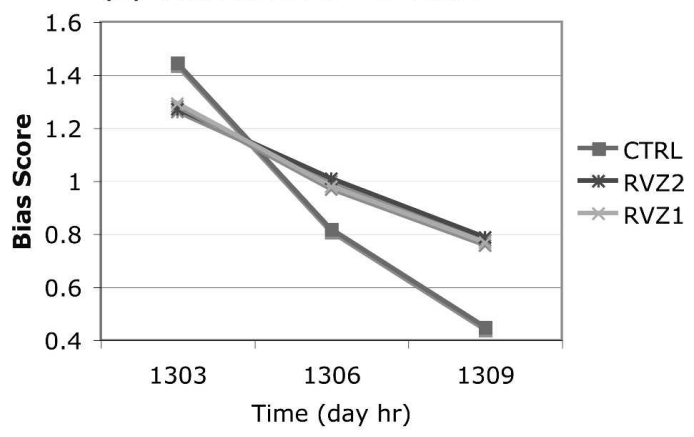

(f) Threshold $=10 \mathrm{~mm}$

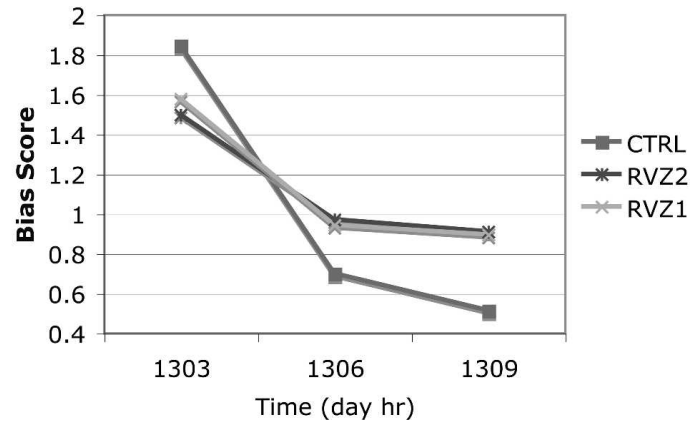

FIG. 12. Comparison of TSs for the 3-h accumulated precipitation among the three experiments (CTRL, RVZ1, and RVZ2) with thresholds of (a) 1, (b) 5 , and (c) $10 \mathrm{~mm}$; and bias scores with thresholds of (d) 1, (e) 5, and (f) $10 \mathrm{~mm}$. The QPF verification is performed against the NCEP stage IV precipitation analysis in the thick rectangular box shown in Fig. 4 and the domain for Fig. 2.

June. The convection after 0900 UTC diminished and hence we did not conduct QPF verification. Figure 12 clearly indicates that assimilation of Doppler radar data (RVZ1 and RVZ2) gives consistently higher scores than CTRL for both light and heavy rainfall. The biases in RVZ1 and RVZ2 are also smaller than in CTRL. The 3-hourly 3DVAR cycling of Doppler radar data at 2100 UTC 12 June and 0000 UTC 13 June in RVZ2 produces a higher TS than the one-time assimilation at 0000 UTC 13 June in RVZ1. In addition, RVZ2 has a smaller bias than does RVZ1 in the verifications with thresholds of 5 and $10 \mathrm{~mm}$. The three experiments
(CTRL, RVZ1, and RVZ2) obtain the highest TSs in the short range $(3 \mathrm{~h})$ for light rainfall. But for heavy rainfall (thresholds of 5 and $10 \mathrm{~mm}$ ), the highest TSs are obtained at the 6-h prediction. The biases in the 6-h rainfall prediction are also the smallest, while 3-h rainfalls are overpredicted and 9-h totals are underpredicted.

This set of experiments suggests that the 3DVAR cycling of Doppler radar observations enhances the QPF skill. More benefits are obtained for heavy rainfall. The assimilation of Doppler radar data is especially important for the extended short-range (6 h) QPF for 
(a) Threshold $=1 \mathrm{~mm}$

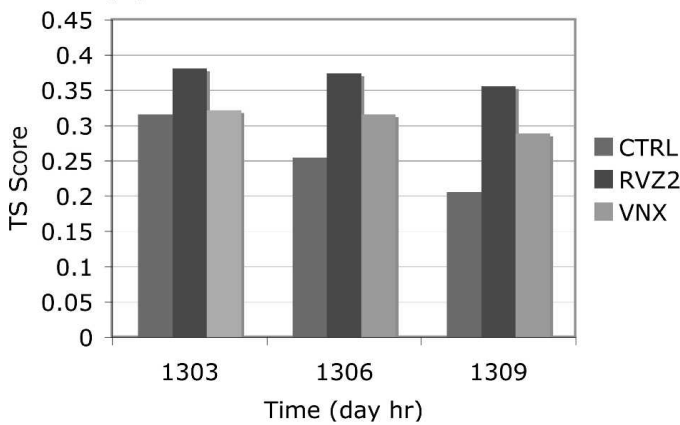

(b) Threshold $=5 \mathrm{~mm}$

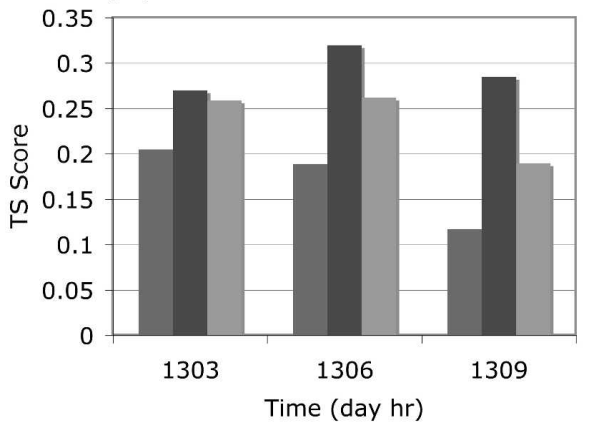

(c) Threshold $=10 \mathrm{~mm}$

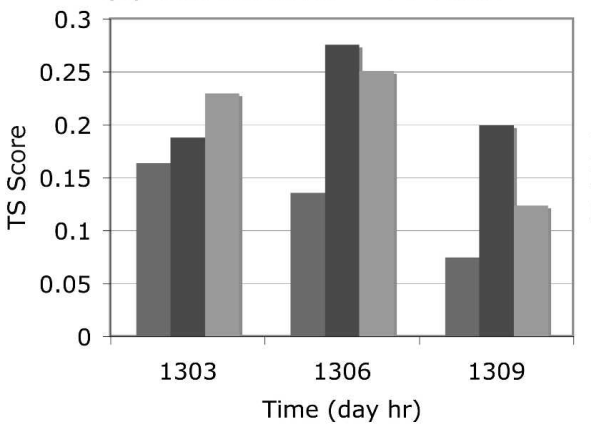

(d) Threshold $=1 \mathrm{~mm}$

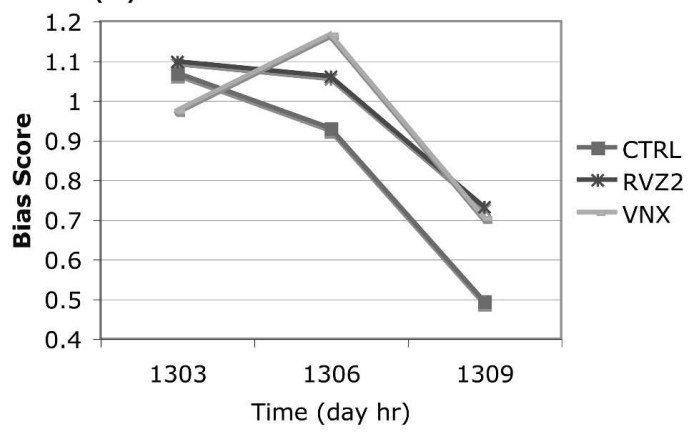

(e) Threshold $=5 \mathrm{~mm}$

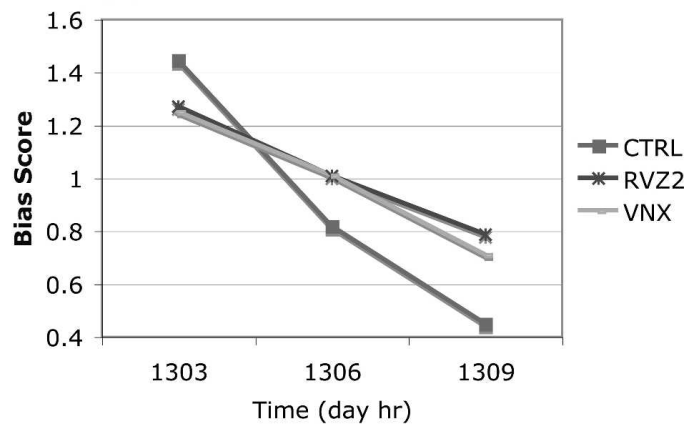

(f) Threshold $=10 \mathrm{~mm}$

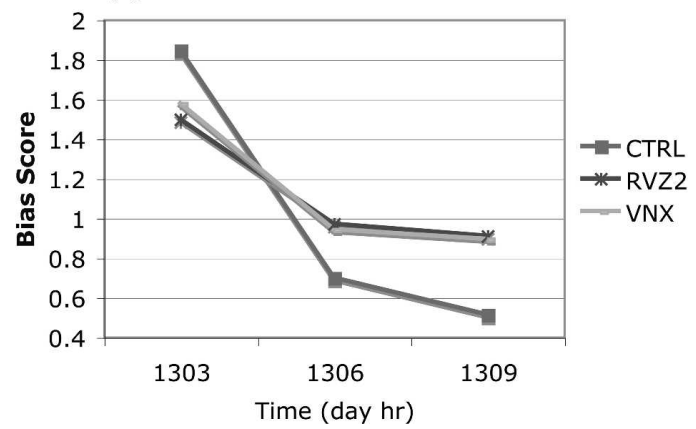

FIG. 13. Comparison of TSs for the 3-h accumulated precipitation among the three experiments (CTRL, RVZ2, and VNX) with thresholds of (a) 1, (b) 5, and (c) $10 \mathrm{~mm}$; and bias scores with thresholds of (d) 1, (e) 5, and (f) 10 $\mathrm{mm}$. The QPF verification is performed against the NCEP stage IV precipitation analysis in the thick rectangular box shown in Fig. 4 and the domain for Fig. 2.

heavy rainfall. Note that there is still value in the 9-h forecast from radar data assimilation using the WRF 3DVAR system.

\section{b. Multiple-radar versus single-radar assimilation}

The impact of multiple- versus single-Doppler radar data on the ARW QPF skill is assessed in Fig. 13. Generally speaking, the TSs of the experiment VNX (single-Doppler radar data) are lower than those of RVZ2 (data from 12 Doppler radars), but higher than those of CTRL. The exception is at 0300 UTC 13 June when VNX obtains a higher TS than does RVZ2 for heavy rainfall with the threshold of $10 \mathrm{~mm}$. Both singleDoppler radar experiment VNX and multiple-radar experiment RVZ2 reduced the biases from CTRL. The overall bias of RVZ2 is smaller than that of VNX, especially for heavy rainfall prediction. Since the single Doppler radar [at Vance Air Force Base (AFB), Oklahoma] captures the major convection in the rainfall band at both 2100 UTC 12 June (Fig. 1a) and 0000 UTC 13 June (Fig. 1b), the assimilation of this singleDoppler radar data produces a notable improvement in the QPF skill. With more data from other radar sta- 
(a) Threshold $=1 \mathrm{~mm}$

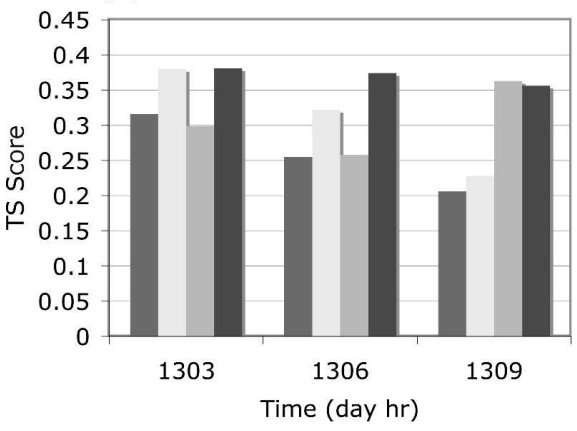

(b) Threshold $=5 \mathrm{~mm}$

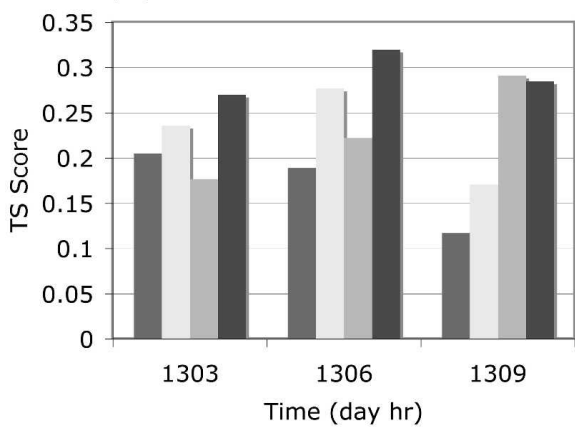

(c) Threshold $=10 \mathrm{~mm}$

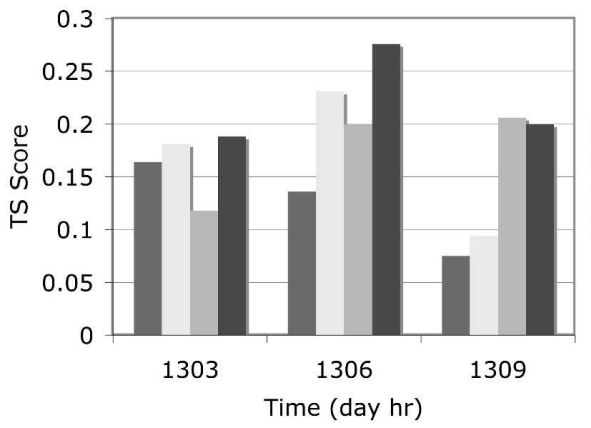

(d) Threshold $=1 \mathrm{~mm}$

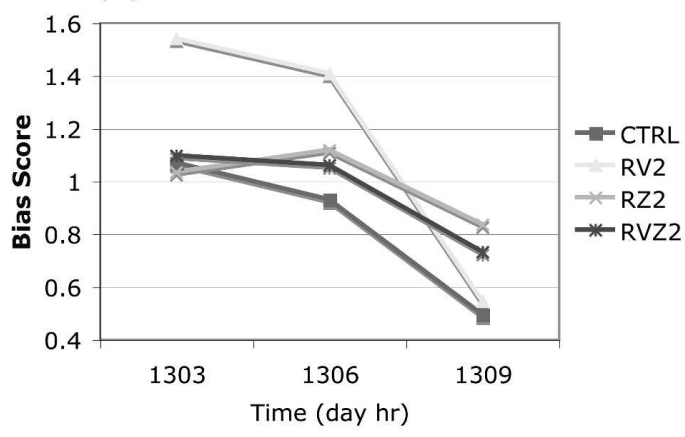

(e) Threshold $=5 \mathrm{~mm}$

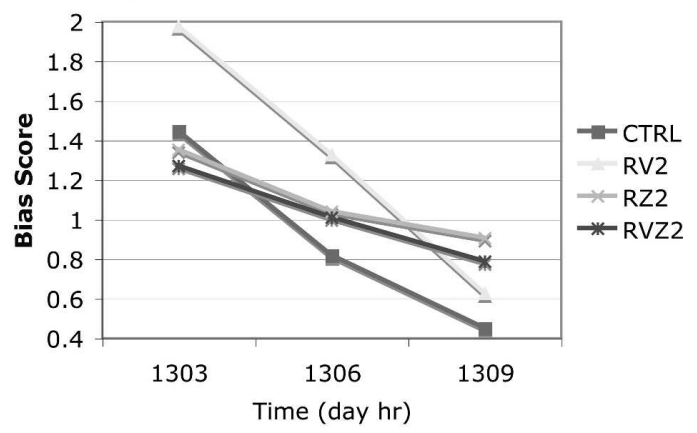

(f) Threshold $=10 \mathrm{~mm}$

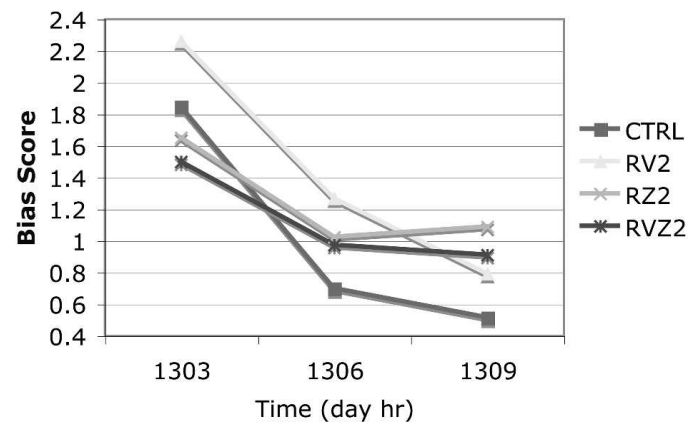

FIG. 14. Comparison of threat scores for the 3-h accumulated precipitation among the four experiments (CTRL, RV2, RZ2, and RVZ2) with the threshold of (a) 1, (b) 5, and (c) $10 \mathrm{~mm}$; and bias scores with thresholds of (d) 1 , (e) 5 , and (f) $10 \mathrm{~mm}$. The QPF verification is performed against the NCEP stage IV precipitation analysis in the thick rectangular box shown in Fig. 4 and the domain for Fig. 2.

tions, the TSs are further increased and the biases are further reduced. These experiments indicate that the multiple-Doppler radar data assimilation has added benefits for the subsequent QPF compared to singleDoppler radar data assimilation.

\section{c. Assimilation of Doppler radial velocity and/or reflectivity}

Comparing the TSs of different experiments shown in Fig. 14 leads to the following observations on the QPF verification. First, assimilation of both radial ve- locity and reflectivity (RVZ2) results in the highest TSs, at 0300 and 0600 UTC, among all of the experiments. RVZ2 has the smallest bias for heavy rainfall with the threshold of $10 \mathrm{~mm}$ as well. Second, assimilation of the radial velocity (RV2) produces higher TSs than does assimilation of the reflectivity for the prediction of the 3- and 6-h rainfall, but assimilation of the reflectivity (RF2) produces a higher TS at 0900 UTC, even higher than that of RVZ2. Note that the higher TS in RV2 is perhaps due to the rainfall overprediction; the biases of RV2 at 0300 and 0600 UTC are much larger than in the other experiments. Third, assimila- 


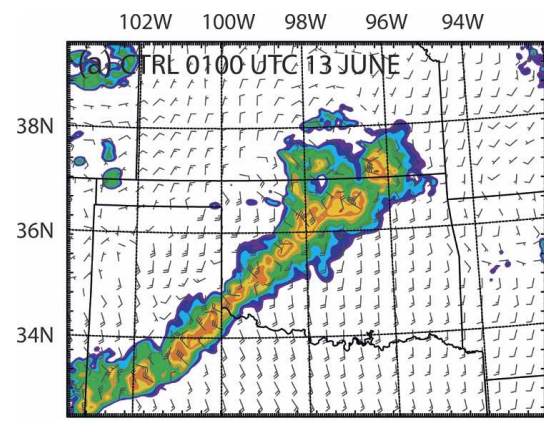

102W 100W 98W 96W 94W

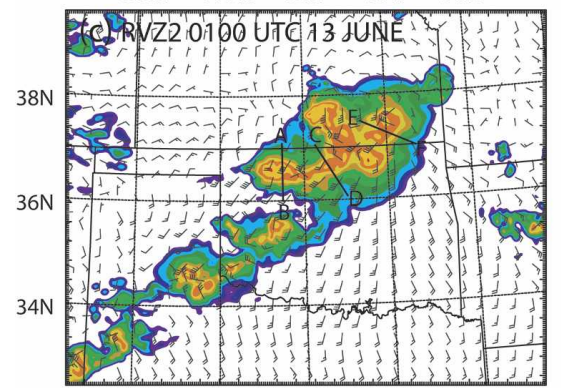

$100 \mathrm{~W}$

$95 \mathrm{~W}$

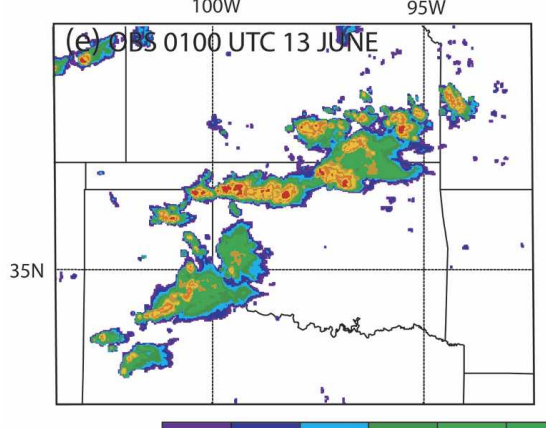

102W 100W 98W 96W 94W

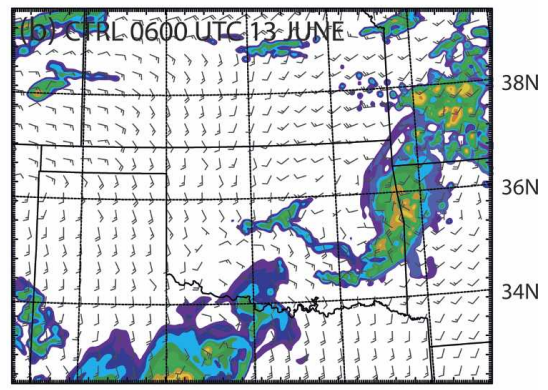

102W 100W 98W 96W 94W

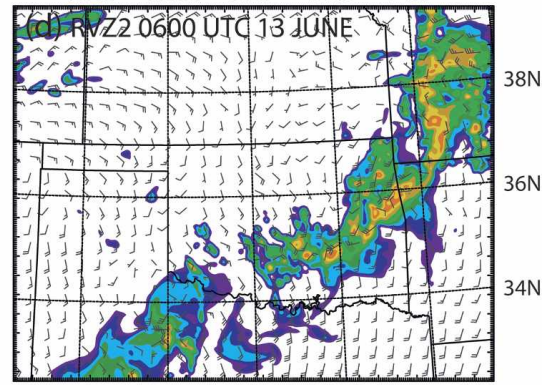

$100 \mathrm{~W}$

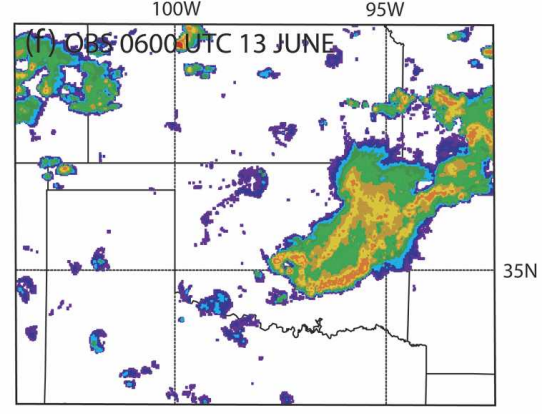

FIG. 15. Simulated reflectivity fields by CTRL at (a) 0100 and (b) 0600 UTC, by RVZ2 at (c) 0100 and (d) 0600 UTC, and the reflectivity observations from the WSR-88D radar network at (e) 0100 and (f) 0600 UTC 13 Jun. The color bar for the reflectivity fields is shown at the bottom of the figure. The simulated wind barbs (a full barb represents $5 \mathrm{~m} \mathrm{~s}^{-1}$ ) are overlapped in (a)-(d). The lines AB, CD, and EF in (c) are used for the cross sections shown in Fig. 17.

tion of the reflectivity has a negative impact on the TS at 0300 UTC 13 June compared with CTRL (the 6- and 9-h TSs are improved from CTRL). The overall bias of RZ2 is smaller than that of RV2. These results indicate that (a) assimilation of radial winds (RV2) enhances the TSs, but also increases biases for short-range QPF due to rainfall overprediction; (b) an initial imbalance exists in the reflectivity assimilation experiment RZ2, even though the analysis fits optimally to the reflectivity observations; and (c) the relatively simple microphysics (warm rain process) used in the 3DVAR partitioning scheme is not consistent with the ARW model microphysics (i.e., the WSM6 scheme) and a positive impact is obtained only after a period of adjustment during the model integration.

\section{Further assessment of the forecasted squall line}

We showed that the initialization with two-time, multiple-Doppler radar data assimilation produces a sound analysis and improved QPF skill. Does the initialization result in a better squall-line structure in the subsequent forecast? In this section, we analyze the results from the experiment RVZ2 to answer this question.

Figure 15 shows the simulated reflectivity patterns at 0100 and 0600 UTC 13 June from experiments CTRL and RVZ2, as well as the observations from the U.S. WSR-88D radar network. Recall that the CTRL experiment analyzes a line of convection along the dryline at 0000 UTC 13 June, but RVZ2 produces an analysis with some mesoscale structures and patterns that are 

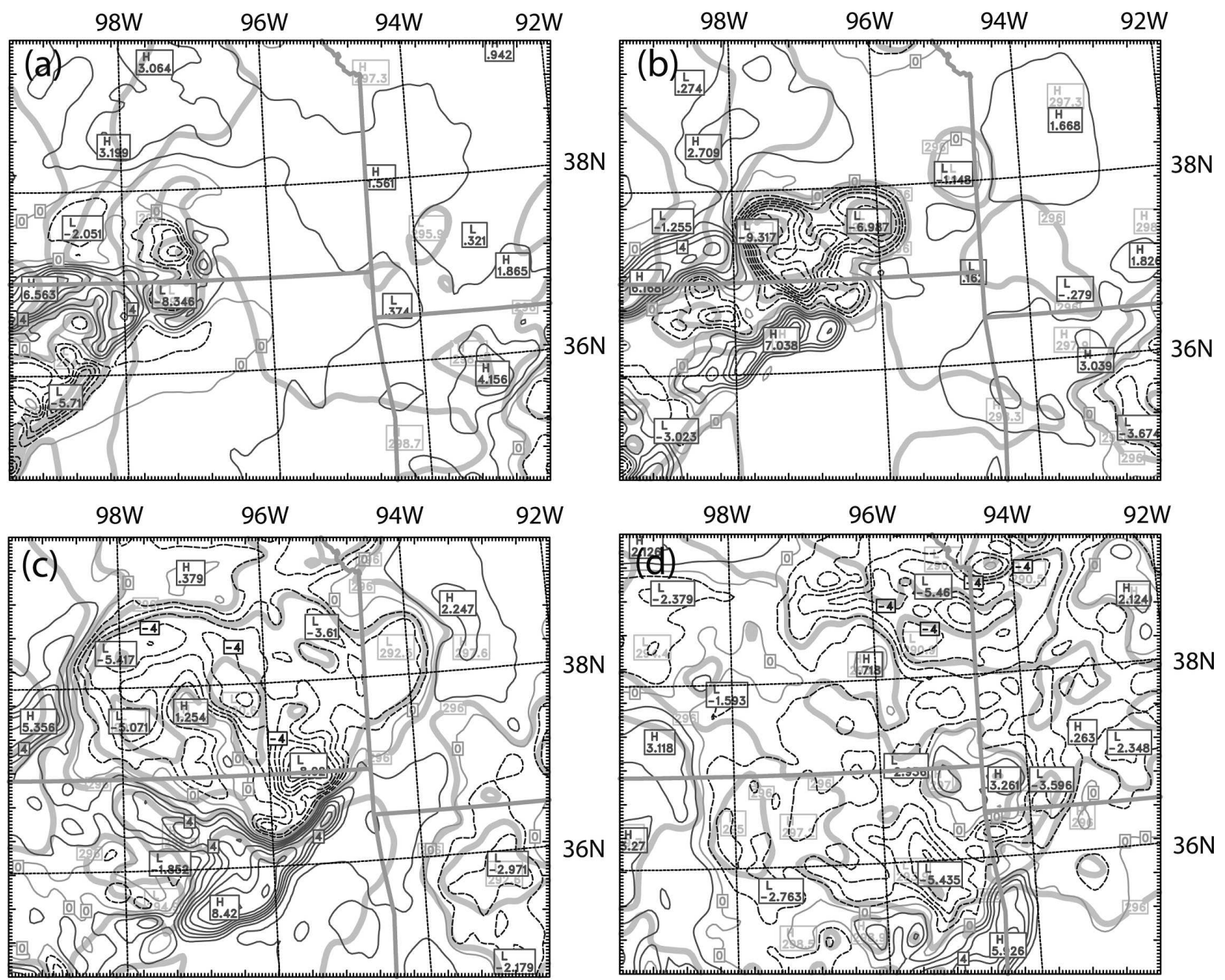

FIG. 16. The temperature (gray thick isolines with intervals of $2 \mathrm{~K}$ ) and temperature difference from CTRL (thin isolines with intervals of $1 \mathrm{~K}$ ) for RVZ2 at $500 \mathrm{~m}$ AGL at (a) 0000, (b) 0100, (c) 0300, and (d) 0600 UTC 13 Jun.

much closer to the observations. The 1-h prediction of CTRL (Fig. 15a) still shows a strong convective line along the dryline, which is much different from the observations (Fig. 15e). In the 6-h forecast, a large part of the simulated convection in Oklahoma dissipates (Fig. 15b). On the contrary, however, the observation still shows a strong convective system within Oklahoma (Fig. 15f). RVZ2 demonstrates much better simulations than CTRL. At 0100 UTC, the squall line along the Oklahoma-Kansas border was simulated, which is similar to the observations. Particularly, we should point out that the pattern from northern Oklahoma to the northeastern tip of the Texas Panhandle in Fig. 15e is produced in Fig. 15c, even though the extension to the northeastern tip of the Texas Panhandle is a little shorter than the observations. At 0600 UTC, the prediction of RVZ2 still shows a solid squall-line pattern (Fig. 15d). Although the location and the orientation are slightly off when compared with the observations (Fig. 15f), the convective line at the leading edge of the cold pool is simulated reasonably well. The cold pool structure will be analyzed in the following paragraph.

The analyses of the CTRL and RVZ2 experiments both clearly indicate that a warm and moist zone is initiated at 0000 UTC 13 June from Texas across Oklahoma to Kansas (figure omitted). However, at the lower levels in the area to the north of the midOklahoma-Kansas border, RVZ2 is colder than CTRL. To show this feature and its subsequent evolution, we plot the temperature differences between RVZ2 and CTRL at $500 \mathrm{~m}$ above ground level (AGL) at 0000, 0100, 0300, and 0600 UTC 13 June in Fig. 16. At the initial time (0000 UTC), the temperature of RVZ2 in the area near the mid-Oklahoma-Kansas border is over $-8^{\circ} \mathrm{C}$ colder than IN CTRL (Fig. 16a), suggesting an 

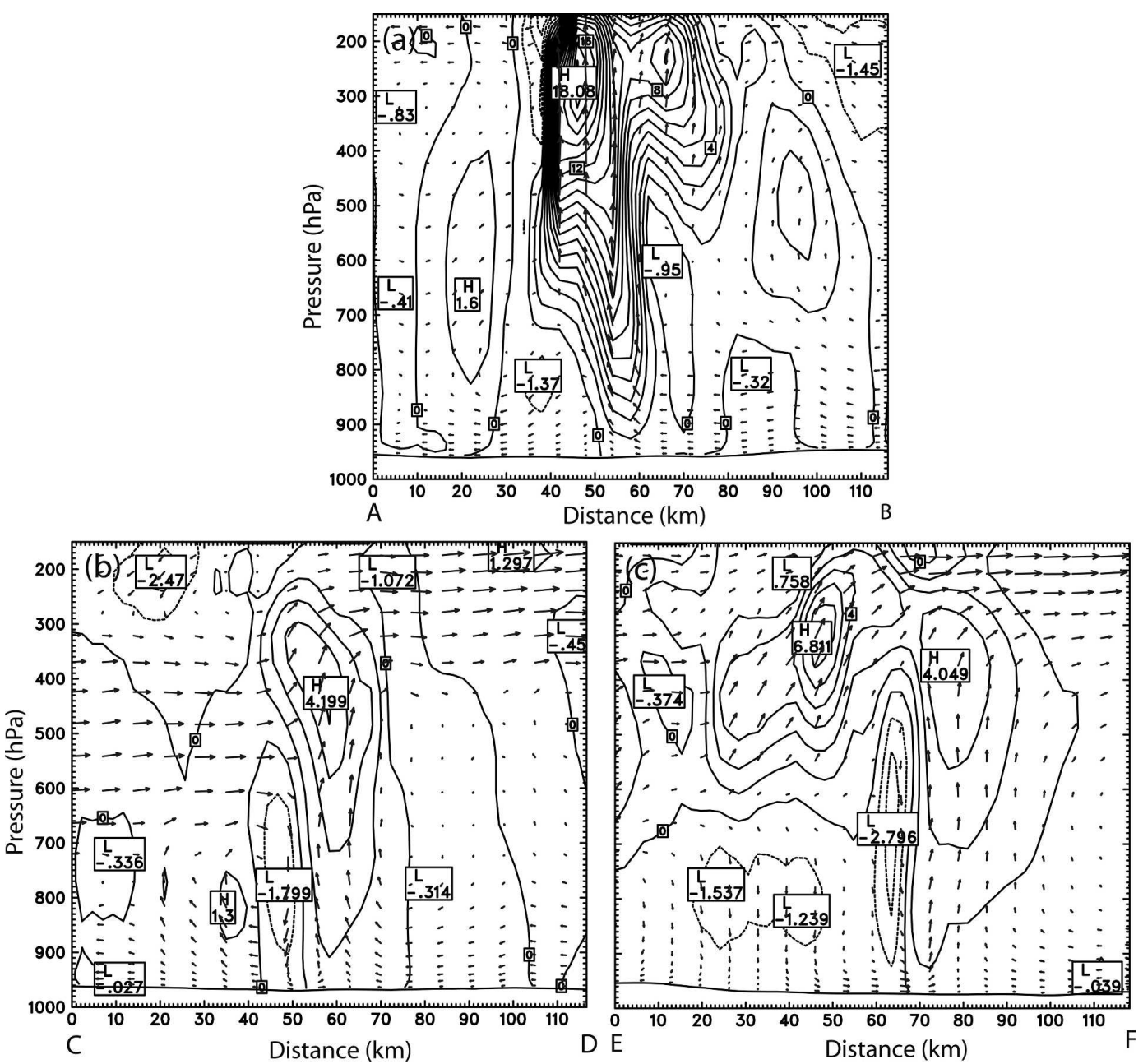

FIG. 17. Cross sections of the vertical velocity and velocity vectors along (a) AB, (b) CD, and (c) EF in Fig. 15c at 0100 UTC 13 Jun by RVZ2. The CI of the vertical velocity isolines is $1 \mathrm{~m} \mathrm{~s}^{-1}$ and the negative lines are dashed.

analyzed cold pool in the initialization. After the ARW integration, the cold pool becomes more evident at 0100 UTC (Fig. 16b), and evolves and translates southeastward (Figs. 16b-d). The temperature difference of the cold pool reaches over $-9^{\circ} \mathrm{C}$ at 0100 UTC, over $-8^{\circ} \mathrm{C}$ at $0300 \mathrm{UTC}$, and $-3^{\circ}$ to $-5^{\circ} \mathrm{C}$ at $0600 \mathrm{UTC}$. The convection at the southeastern frontier of the cold pool is better generated in RVZ2 than in CTRL, and RVZ2 still shows a solid squall-line structure at 0600 UTC (Fig. 15d), while a large part of the convection in CTRL dissipates at that time (Fig. 15b). The stronger cold pool simulated in RVZ2 is the major cause for the difference. The cold pool expands further at 0300 and 0600 UTC (Figs. 16c and 16d) compared with that at 0100 UTC (Fig. 16b). New cells are triggered on the northeast-to-southwest-oriented leading edge of the cold pool, which moved the squall line southeastward during its life span.
To further analyze the squall-line structure, Fig. 17 presents the cross section of the vertical velocity and velocity vectors of RVZ2 at 0100 UTC 13 June along lines $\mathrm{AB}, \mathrm{CD}$, and $\mathrm{EF}$, as shown in Fig. 15c. It is shown that the upward motion is above the simulated squall line and the downward motion exists behind (on the north or northwest side of the precipitation region). The magnitudes of the upward and downward motions are different at different cross sections along $\mathrm{AB}, \mathrm{CD}$, and EF. Along the line AB shown in Fig. 15c, the upward motion above the simulated squall line is the strongest (Fig. 17a), and the maximum vertical velocity reaches $18.08 \mathrm{~m} \mathrm{~s}^{-1}$ at around $300 \mathrm{hPa}$. The main upward vertical velocities above the squall line reach $4.199 \mathrm{~m} \mathrm{~s}^{-1}$ along CD at around $400 \mathrm{hPa}$ (Fig. 17b), and $6.811 \mathrm{~m} \mathrm{~s}^{-1}$ along EF at around $350 \mathrm{hPa}$ (Fig. 17c). Even though the upward motion is the strongest along $\mathrm{AB}$, its downdraft behind is the weakest among the 
three cross sections. The cross section along EF shows a broad and strong downdraft. The airflow structure in Fig. 17 shows very typical characteristics of a squall-line convective system (Zipser 1977), indicating the squall line in RVZ2 is well simulated. The downdraft behind the squall line is responsible for the cold pool formation. The southeastward translation of the cold pool is responsible for the squall-line evolution in the subsequent forecast. Since the downdraft along $\mathrm{AB}$ is the weakest, the convection in this area has the quickest dissipation even though it has the strongest convection in the beginning. The broad and strong downdraft along EF produced the cold pool in Fig. 16, and the convection in the area has the longest life span. The major squall-line convection is generated from the leading edge of the cold pool and propagates along the EF axis.

\section{Summary and conclusions}

The multiple-Doppler radar data assimilation capability in the WRF 3DVAR system is developed and tested. The 12-13 June 2002 squall line observed during the IHOP_2002 campaign is used as the test case. Doppler radar data from 12 radar sites over the Great Plains are acquired and preprocessed (quality control, thinning, mapping, and error estimation). The resolution of the WRF 3DVAR analyses and the ARW forecast is $4 \mathrm{~km}$, and the experiment domain covers the extended U.S. Great Plains. In this study, we have evaluated the capability of multiple-Doppler radar data assimilation with the WRF 3DVAR in cycling mode in the short-range QPF of the squall line and its structures. Major conclusions from this IHOP_2002 squall-line case study are summarized as follows.

1) The WRF 3DVAR system can successfully assimilate the Doppler radial velocity and reflectivity from multiple Doppler radar sites. The single-observation test indicates that the analysis increment response to the radial velocity assimilation is dynamically consistent, and vertical velocity can be produced by the radial velocity assimilation. The analysis increment response to the reflectivity assimilation is complex but reasonable, and the hydrometeor increments can be produced by the reflectivity assimilation. The hydrometeor analysis increments are usually asymmetric and background dependent. The inclusion of the hydrometeor increments in the WRF 3DVAR multivariate correlation structure is vital for the radar reflectivity assimilation.

2) Assimilation experiments indicate that radial velocity has a large impact on the wind and vertical ve- locity analyses, and its impact on moisture and hydrometeor analyses is secondary. On the other hand, radar reflectivity has a direct impact on the moisture and hydrometeor analyses, and its impact on the wind and vertical velocity analyses is secondary. When both radial velocity and reflectivity are assimilated, we obtained sound analyses that have adjustments in both the dynamical and thermodynamical fields that are consistent with the WRF 3DVAR constraint and background error correlation.

3) Cycling of the Doppler radar data from the 12 radar sites at 2100 UTC 12 June and 0000 UTC 13 June produces a much more organized pattern in the squall-line analysis at 0000 UTC 13 June, compared with the experiment with the one-time data assimilation. The horizontal and vertical wind analyses with the radial velocity assimilation, and the moisture and hydrometeor analyses with the reflectivity assimilation, have more detailed mesoscale structures in the squall line and its related dryline system.

4) Since the background error statistics are computed using the ensemble forecasts of the same case, these statistics are a good representative for this case. Therefore, the ARW QPF skills are improved with the assimilation of multiple radar observations at different times and locations. It should be pointed out that using case-dependent ensemble background error statistics is very time consuming, and it is not practical for real-time operations at the current stage. For research purposes, it is also necessary to conduct more case studies for verification.

5) For the squall-line case, the multiple-Doppler radar data assimilation experiment has a better initiation of the cold pool structure in the area to the north of the mid-Oklahoma-Kansas border. Since the cold pool and its related squall-line triggering process is better initiated and simulated, we obtained better squall-line structures and improved ARW QPF skill in the multiple-Doppler radar cycling experiment compared with other experiments.

Although the results presented in this paper demonstrate that the assimilation of multiple-Doppler radar data with the WRF 3DVAR system has the potential to improve QPF skill, there are several obstacles to its real-time operations, such as a practical method for generating the background error statistics, the automatic quality control of the radar data, and the inclusion of the ice-phase microphysics in WRF 3DVAR. In this study, we also note that there are some spurious, scattered convective cells in the simulation. The extension of the squall-line convection at the northeastern tip of the Texas Panhandle is shorter than in the observa- 
tions (Fig. 15c). The convection in the multipleDoppler radar data assimilation still dissipates earlier than in the observations. The location and orientation of the squall line are slightly off when compared with the observations. Further improvement of the scheme and more case studies to evaluate the system's capability are needed in the future.

Acknowledgments. We are grateful to Andrew Crook, Dale Barker, Chris Snyder, Ying-Hwa Kuo, and So-Young Ha of NCAR/MMM; Soichiro Sugimuto of Japan's Central Research Institute of Electric Power Industry; Jianfeng $\mathrm{Gu}$ of the Shanghai Weather Forecasting Center of China; and Mi-seon Lee from the Korea Meteorological Administration for their constructive suggestions and help in our experiments and analysis of the results. The comments on our initial draft of this work by our colleagues Tammy Weckwerth, Dale Barker, and Sophie Bastin are greatly acknowledged. This research is supported by the U.S. Weather Research Program (USWRP).

\section{REFERENCES}

Barker, D. M., W. Huang, Y.-R. Guo, A. Bourgeois, and Q. Xiao, 2004: A three-dimensional variational (3DVAR) data assimilation system for MM5: Implementation and initial results. Mon. Wea. Rev., 132, 897-914.

Courtier, P., J. N. Thepaut, and A. Hollingsworth, 1994: A strategy for operational implementation of 4D-Var using an incremental approach. Quart. J. Roy. Meteor. Soc., 120, 13671387.

Dowell, D. C., F. Zhang, L. J. Wicker, C. Snyder, and N. A. Crook, 2004: Wind and temperature retrievals in the 17 May 1981 Arcadia, Oklahoma, supercell: Ensemble Kalman filter experiments. Mon. Wea. Rev., 132, 1982-2005.

Dudhia, J., 1989: Numerical study of convection observed during the Winter Monsoon Experiment using a mesoscale twodimensional model. J. Atmos. Sci., 46, 3077-3107.

Evensen, G., 1994: Sequential data assimilation with a nonlinear quasi-geostrophic model using Monte Carlo methods to forecast error statistics. J. Geophys. Res., 99 (C5), 10 143-10 162.

Fisher, M., 1999: Background error statistics derived from an ensemble of analyses. ECMWF Research Department Tech. Memo. 79, 12 pp.

Fritsch, J. M., and R. E. Carbone, 2004: Improving quantitative precipitation forecasts in the warm season: A USWRP research and development strategy. Bull. Amer. Meteor. Soc., 85, 955-965.

Gao, J., M. Xue, A. Shapiro, and K. Droegemeier, 1999: A variational method for the analysis of three-dimensional wind fields from two Doppler radars. Mon. Wea. Rev., 127, 21282142.

,-- K. Brewster, and K. K. Droegemeier, 2004: A threedimensional variational data analysis method with recursive filter for Doppler radars. J. Atmos. Oceanic Technol., 21, 457-469.

Germann, U., and I. Zawadski, 2002: Scale-dependence of the predictability of pecipitation from continental radar images. Part I: Description of the methodology. Mon. Wea. Rev., 130, 2859-2873.

Hayden, C. M., and R. J. Purser, 1995: Recursive filter objective analysis of meteorological fields: Applications to NESDIS operational processing. J. Appl. Meteor., 34, 3-15.

Hong, S.-Y., and H.-L. Pan, 1996: Nonlocal boundary layer vertical diffusion in a medium-range forecast model. Mon. Wea. Rev., 124, 2322-2339.

Hu, M., M. Xue, and K. Brewster, 2006: 3DVAR and cloud analysis with WSR-88D level-II data for the prediction of the Fort Worth, Texas, tornadic thunderstorms. Part I: Cloud analysis and its impact. Mon. Wea. Rev., 134, 675-698.

Ide, K., P. Courtier, M. Ghil, and A. C. Lorenc, 1997: Unified notation for data assimilation: Operational, sequential and variational. J. Meteor. Soc. Japan, 75, 181-189.

Lee, M.-S., D. M. Barker, and Y.-H. Kuo, 2006: Background error statistics using WRF ensembles generated by randomized control variables. J. Kor. Meteor. Soc., 42, 153-167.

Lin, Y.-L., R. D. Farley, and H. D. Orville, 1983: Bulk parameterization of the snow field in a cloud model. J. Climate Appl. Meteor., 22, 1065-1092.

Lorenc, A. C., and Coauthors, 2000: The Met. Office global threedimensional variational data assimilation scheme. Quart. J. Roy. Meteor. Soc., 126, 2991-3012.

Mlawer, E. J., S. J. Taubman, P. D. Brown, M. J. Iacono, and S. A. Clough, 1997: Radiative transfer for inhomogeneous atmosphere: RRTM, a validated correlated-k model for the longwave. J. Geophys. Res., 102 (D14), 16 663-16 682.

Purser, R. J., W.-S. Wu, D. F. Parrish, and N. M. Roberts, 2003: Numerical aspects of the application of recursive filters to variational statistical analysis. Part I: Spatially homogeneous and isotropic Gaussian covariances. Mon. Wea. Rev., 131, 1524-1535.

Richardson, L. F., 1922: Weather Prediction by Numerical Process. Cambridge University Press, 236 pp.

Shapiro, A., S. Ellis, and J. Shaw, 1995: Single-Doppler velocity retrievals with Phoenix II data: Clear air and microburst wind retrievals in the planetary boundary layer. J. Atmos. Sci., 52, $1265-1287$.

Skamarock, W. C., J. B. Klemp, J. Dudhia, D. O. Gill, D. M. Barker, W. Wang, and J. G. Powers, 2005: A description of the Advanced Research WRF version 2. NCAR Tech. Note NCAR/TN-468+STR, 88 pp.

Snyder, C., and F. Zhang, 2003: Assimilation of simulated Doppler radar observations with an ensemble Kalman filter. Mon. Wea. Rev., 131, 1663-1677.

Sun, J., 2005: Initialization and numerical forecasting of a supercell storm observed during STEPS. Mon. Wea. Rev., 133, 793 813.

— , and N. A. Crook, 1997: Dynamical and microphysical retrieval from Doppler radar observations using a cloud model and its adjoint. Part I: Model development and simulated data experiments. J. Atmos. Sci., 54, 1642-1661.

— and - 1998: Dynamical and microphysical retrieval from Doppler radar observations using a cloud model and its adjoint. Part II: Retrieval experiments of an observed Florida convective storm. J. Atmos. Sci., 55, 835-852.

Tong, M., and M. Xue, 2005: Ensemble Kalman filter assimilation of Doppler radar data with a compressible nonhydrostatic model: OSS experiments. Mon. Wea. Rev., 133, 1789-1807.

Wakimoto, R. M., H. V. Murphey, and R. G. Fovell, 2004: Mantle 
echoes associated with deep convection: Observations and numerical simulations. Mon. Wea. Rev., 132, 1701-1720.

Weygandt, S. S., A. Shapiro, and K. K. Droegemeier, 2002a: Retrieval of model initial fields from single-Doppler observations of a supercell thunderstorm. Part I: Single-Doppler velocity retrieval. Mon. Wea. Rev., 130, 433-453.

$\ldots, \ldots$, and — 2002b: Retrieval of model initial fields from single-Doppler observations of a supercell thunderstorm. Part II: Thermodynamic retrieval and numerical prediction. Mon. Wea. Rev., 130, 454-476.

Weckwerth, T. M., and Coauthors, 2004: An overview of the International $\mathrm{H}_{2} \mathrm{O}$ Project (IHOP_2002) and some preliminary highlights. Bull. Amer. Meteor. Soc., 85, 253-277.

Xiao, Q., Y.-H. Kuo, J. Sun, W.-C. Lee, E. Lim, Y.-R. Guo, and D. M. Barker, 2005: Assimilation of Doppler radar observations with a regional 3DVAR system: Impact of Doppler velocities on forecasts of a heavy rainfall case. J. Appl. Meteor., 44, 768-788.

,,,---- D. M. Barker, and E. Lim, 2007: An approach of Doppler reflectivity assimilation and its assessment with the inland QPF of Typhoon Rusa (2002) at landfall. $J$. Appl. Meteor. Climatol., 46, 14-22.

Zhang, F., C. Snyder, and J. Sun, 2004: Impacts of initial estimate and observation availability on convective-scale data assimilation with an ensemble Kalman filter. Mon. Wea. Rev., 132, 1238-1253.

Ziegler, C. L., 1985: Retrieval of thermal and microphysical variables in observed convective storms. Part I: Model development and preliminary testing. J. Atmos. Sci., 42, 1487-1509.

Zipser, E. J., 1977: Mesoscale and convective-scale downdrafts as distinct components of squall-line structure. Mon. Wea. Rev., 105, 1568-1589. 